\title{
Long-term changes and variability in a transient simulation with a chemistry-climate model employing realistic forcing
}

\author{
M. Dameris ${ }^{1}$, V. Grewe ${ }^{1}$, M. Ponater ${ }^{1}$, R. Deckert ${ }^{1}$, V. Eyring ${ }^{1}$, F. Mager ${ }^{1, *}$, S. Matthes ${ }^{1}$, C. Schnadt ${ }^{1, * *}$, A. Stenke ${ }^{1}$, \\ B. Steil ${ }^{2}$, C. Brühl ${ }^{2}$, and M. A. Giorgetta ${ }^{3}$ \\ ${ }^{1}$ Institut für Physik der Atmosphäre, DLR-Oberpfaffenhofen, Wessling, Germany \\ ${ }^{2}$ Max-Planck-Institut für Chemie, Mainz, Germany \\ ${ }^{3}$ Max-Planck-Institut für Meteorologie, Hamburg, Germany \\ * now at: University of Cambridge, Centre for Atmospheric Science, Department of Geography, Cambridge, UK \\ ** now at: ETH Zürich, Institut für Atmosphäre und Klima, Zürich, Switzerland
}

Received: 25 January 2005 - Published in Atmos. Chem. Phys. Discuss.: 14 April 2005

Revised: 29 June 2005 - Accepted: 1 August 2005 - Published: 11 August 2005

\begin{abstract}
A transient simulation with the interactively coupled chemistry-climate model (CCM) E39/C has been carried out which covers the 40-year period between 1960 and 1999. Forcing of natural and anthropogenic origin is prescribed where the characteristics are sufficiently well known and the typical timescales are slow compared to synoptic timescale so that the simulated atmospheric chemistry and climate evolve under a "slowly" varying external forcing. Based on observations, sea surface temperature (SST) and ice cover are prescribed. The increase of greenhouse gas and chlorofluorocarbon concentrations, as well as nitrogen oxide emissions are taken into account. The 11-year solar cycle is considered in the calculation of heating rates and photolysis of chemical species. The three major volcanic eruptions during that time (Agung, 1963; El Chichon, 1982; Pinatubo, 1991) are considered. The quasi-biennial oscillation (QBO) is forced by linear relaxation, also known as nudging, of the equatorial zonal wind in the lower stratosphere towards observed zonal wind profiles. Beyond a reasonable reproduction of mean parameters and long-term variability characteristics there are many apparent features of episodic similarities between simulation and observation: In the years 1986 and 1988 the Antarctic ozone holes are smaller than in the other years of that decade. In mid-latitudes of the Southern Hemisphere ozone anomalies resemble the corresponding observations, especially in 1985, 1989, 1991/1992, and 1996. In the Northern Hemisphere, the episode between the late 1980s and the first half of the 1990s is dynamically quiet, in particular, no stratospheric warming is found between 1988 and 1993. As observed, volcanic eruptions strongly influence dynamics and chemistry, though only for
\end{abstract}

Correspondence to: M. Dameris

(Martin.Dameris@dlr.de) few years. Obviously, planetary wave activity is strongly driven by the prescribed SST and modulated by the QBO. Preliminary evidence of realistic cause and effect relationships strongly suggests that detailed process-oriented studies will be a worthwhile endeavour.

\section{Introduction}

In recent years, more and more results of interactively coupled chemistry-climate models (CCMs) have become available (e.g. Rozanov et al., 2001; Austin, 2002; Nagashima et al., 2002; Pitari et al., 2002; Schnadt et al., 2002; Steil et al., 2003; Manzini et al., 2003). First of all, they have been developed to examine the feedback between dynamical, physical, and chemical processes in the atmosphere, with a particular focus on the upper troposphere and stratosphere. The primary purpose of CCMs is to support analyses of longterm observations and to explain recent changes and variability of chemical composition and dynamics. Like other complex model systems, CCMs must be carefully checked with respect to their abilities and deficiencies to describe present and recent atmospheric conditions before they can be applied for reliable estimates of future changes (e.g. Eyring et al., 2005b).

Currently, there are two concepts to perform numerical experiments with CCMs: Firstly, so-called time-slice experiments are well suited to investigate the internal variability of the coupled chemistry-climate system and to indicate and estimate the significance of specific changes of certain parameters or processes in past, present or future climate states with respect to a reference state. Such simulations are carried out with fixed boundary conditions given for a specific year, for

(C) 2005 Author(s). This work is licensed under a Creative Commons License. 
example, concentrations of greenhouse gases (GHGs), emissions of natural and anthropogenic source gases, sea surface temperatures (SSTs), etc., to investigate the corresponding "equilibrium climate". The comparison of time-slice simulations among each other is favourable to identify and interpret long-term temporal developments, e.g., pattern changes, in case that the assessment of statistical significance poses a problem. Secondly, results derived from transient model simulations, which consider observed gradual changes in GHGs and other boundary conditions, allow a more straightforward comparison with the actual temporal development of the real atmosphere. In particular, non-persistent perturbations of the stationary or slowly varying behaviour of the real atmosphere can be included in the simulation for a more detailed model evaluation. Both modelling strategies lead to useful results for a better understanding of atmospheric processes. This is demonstrated by a considerable number of papers which have recently been published (e.g. Rozanov et al., 2001; Austin, 2002; Nagashima et al., 2002; Pitari et al., 2002; Schnadt et al., 2002; Steil et al., 2003; Manzini et al., 2003). A number of examples concerning strengths and weaknesses of CCMs were discussed in Austin et al. (2003) where the results of different CCMs have been compared with observations and each other. The studies mentioned above have concentrated on the stratosphere, others have the main focus on the troposphere (e.g. Wang and Prinn, 1999; Johnson et al., 1999; Grewe et al., 2001a). All these CCM studies have in common that they focus on specific cause and effect relationships with respect to atmospheric chemistry and dynamics, but rarely have tried to investigate the complete system.

It is the central objective of this paper to investigate and discuss the results of a transient simulation with a state-ofthe-art CCM. While E39/C simulates tropospheric and lower stratospheric processes as components of equal importance, the focus of our analysis is on the upper troposphere and lower stratosphere. Although E39/C extends only to about $30 \mathrm{~km}$ and therefore neglects direct influences of the upper stratosphere, we do not believe that this has a significant impact on our conclusions. Possible boundary effects are discussed if appropriate. Moreover, we have tried to include a comprehensive set of external forcings on variability and trends in order to allow a fair comparison with observations and to assess the capability to reproduce the development of the real atmosphere. To our knowledge, this is one of the first transient CCM simulations which, beyond trends in trace gas emissions and concentrations, also considers the forcings from observed sea surface temperature (SST) variability, from large volcanic eruptions, the 11-year solar cycle effect, and the quasi-biennial oscillation (QBO). They all have significant impacts on processes which determine dynamics and chemistry of the atmosphere. This investigation aims to identify and better understand the importance of external forcings on climate and chemical composition. A key question is how deterministic the response of a non-linear model system to such forcings is. However, it is impossible to give a reliable and final answer to this question in a single paper. The employed experimental setup using observed SSTs without additional sensitivity simulations does not allow to determine to what extent the SST development over recent decades is a deterministic response to external forcing and to what extent it resulted from internal variability. This would require at least ensemble simulations with E39/C to reduce the level of stochastic variability, while use of a coupled interactive ocean would be even more favourable. Nevertheless, a detailed comparison of model results and data products derived from long-term observations is presented to advance our understanding of the model's potential and to approach a quantitative answer to this question.

In the following section a brief description of the model and the experimental set-up is given. Section 3 concentrates on long-term changes (trends) in observations and model data. The response due to prescribed forcings (i.e., volcanic eruptions, QBO, solar cycle, SSTs) is discussed in Sect. 4. The results discussed in this paper concentrate on the upper troposphere and lower stratosphere region (UTLS), which is conditioned by the model domain. The last section gives a brief outlook.

\section{Model description and experimental set up}

\subsection{The CCM ECHAM4.L39(DLR)/CHEM}

In this study, the interactively coupled CCM ECHAM4.L39(DLR)/CHEM (hereafter: E39/C) is used for a transient model simulation covering the time period from 1960 to 1999. Previously, the model system has been applied for several investigations, but results from time-slice runs were used exclusively. A basic description of E39/C is given in detail by Hein et al. (2001), Grewe et al. (2001b), and Schnadt et al. (2002). In the following, the setup of $\mathrm{E} 39 / \mathrm{C}$ is only briefly summarised.

The horizontal resolution of E39/C is spectral T30, i.e., dynamical processes have an isotropic resolution of about $670 \mathrm{~km}$. The corresponding Gaussian transform latitudelongitude grid, on which the model physics, chemistry, and tracer transport are calculated, has a mesh size of $3.75^{\circ} \times 3.75^{\circ}$. In the vertical, $\mathrm{E} 39 / \mathrm{C}$ has 39 layers from the surface up to the top layer centred at $10 \mathrm{hPa}$ (Land et al., 2002). The chemistry model CHEM (Steil et al., 1998) is based on a generalised family concept which has three upgrades (Steil et al., 2003): a) reduce the use of the steady state approximation; b) consider coupling between families by solving combined families; and c) definitions of families for transport and chemistry are different. CHEM accounts for relevant stratospheric and tropospheric $\mathrm{O}_{3}$ related homogeneous chemical reactions and heterogeneous chemistry on PSCs and sulphate aerosols. It does not include bromine chemistry. This should influence calculated ozone 
Table 1. Overview of the external forces included in the transient model simulation.

\begin{tabular}{lll}
\hline Forcing & Circulation & Chemistry \\
\hline SST & Real observations - GISS/Hadley & - \\
Volcanoes & Simulated heating rates & Observed/estimated SADs from SAGE \\
QBO & $\begin{array}{l}\text { Zonal stratospheric tropical winds } \\
\text { 'nudged' towards observations }\end{array}$ & - \\
Solar Cycle & Changes in the solar constant & $\begin{array}{l}\text { Changes in extra-terrestrial fluxes (7 bands) } \\
\text { affecting photolysis rates }\end{array}$ \\
$\mathrm{CO}_{2}$ & Greenhouse gas & - \\
$\mathrm{CH}_{4}, \mathrm{~N}_{2} \mathrm{O}, \mathrm{CFCS}$ & Greenhouse gases & $\begin{array}{l}\text { Reaction with OH/photolysis impacts strat. } \\
\text { and trop. chemistry }\end{array}$ \\
$\mathrm{NO}_{\mathrm{x}}$ emissions & - & Impact on ozone chemistry \\
\hline
\end{tabular}

depletion rates, especially in the Northern Hemisphere, since there ozone is only partly destroyed by chlorine. This has to be taken into account when analysing the model results. The model version used in the present study includes updates of the rate coefficients of gas-phase reactions following JPL (2000). Compared to previous model versions, two heterogeneous reactions on stratospheric aerosol have been added $\left(\mathrm{ClONO}_{2}+\mathrm{HCl} \rightarrow \mathrm{Cl}_{2}+\mathrm{HNO}_{3}\right.$ and $\left.\mathrm{HOCl}+\mathrm{HCl} \rightarrow \mathrm{Cl}_{2}+\mathrm{H}_{2} \mathrm{O}\right)$. The transport of chlorine components has been improved by transporting both, total chlorine and the partitioning of chlorine species, to minimise numerical diffusion in regions with lower vertical resolution. As a reminder, this model version does not include complex non-methane hydrocarbon (NMHC) chemistry. It only considers intermediate products of the methane oxidation $\left(\mathrm{CH}_{2} \mathrm{O}, \mathrm{CH}_{3} \mathrm{O}, \mathrm{CH}_{3} \mathrm{O}_{2}\right.$, and the $\mathrm{HO}_{\mathrm{x}}$-family), which are computed at each time-step. The photolysis at solar zenith angles (SZAs) larger than $87.5^{\circ}$ has been implemented into E39/C to account for the effects of twilight stratospheric ozone chemistry. Lamago et al. (2003) showed that modelled temperature as well as ozone fields, particularly in polar regions, improve when SZAs up to $93^{\circ}$ are considered. Net heating rates and photolysis rates in E39/C are calculated from the current modeled three-dimensional (3-D) distributions of the radiatively active gases $\mathrm{O}_{3}, \mathrm{CH}_{4}, \mathrm{~N}_{2} \mathrm{O}, \mathrm{H}_{2} \mathrm{O}$, and CFCs, and the 3-D cloud distribution. The model climatology has been extensively validated; specifically, analyses on the model's performance in the Arctic stratosphere have been carried out (Hein et al., 2001; Austin et al., 2003).

The parameterisation by Price and Rind (1992) used in previous E39/C simulations to account for $\mathrm{NO}_{\mathrm{x}}$ emissions from lightning has been replaced by an improved parameterisation developed by Grewe et al. (2001b). Grewe et al. relate the flash rate to the vertical air mass exchange within a convective cloud. A comparison of flash frequencies calculated by E39/C and those derived from the Optical Transient Detector (OTD) observations onboard the MicroLab satellite showed a qualitatively and quantitatively reasonable agree- ment (Kurz and Grewe, 2002). The parameterisation takes into account intra-cloud and cloud to ground lightning (Price and Rind, 1993) and uses effective $\mathrm{NO}_{\mathrm{x}}$ emission profiles (Pickering et al., 1998). The annual mean emission rate over the 40 -year simulation period amounts to $5.16 \mathrm{Tg}(\mathrm{N}) / \mathrm{a}$.

\subsection{Design of the transient simulation}

The transient integration of E39/C is designed to represent the atmospheric development during the period from 1960 to 1999. A spin-up of ten years with stationary conditions of the late 1950s precedes the actual transient part of the experiment. The simulation aims at reproducing the effect of natural as well as anthropogenic forcings. Natural factors considered are the 11-year solar cycle, the QBO, and chemical and direct radiative effects of the major volcanic eruptions of Agung in 1963, El Chichon in 1982, and Mt. Pinatubo in 1991. The anthropogenic influence is represented by atmospheric concentrations of the most important GHGs, chlorofluorocarbons (CFCs), and nitrogen oxide emissions. Other ozone precursors in the troposphere are not considered. Carbon monoxide (CO) mixing ratios at the Earth surface are prescribed as a function of latitude and season (Hein et al., 1997) and are kept constant throughout this simulation. Table 1 gives an overview of the boundary conditions for the transient simulation.

We emphasize that a considerable part of the anthropogenic impact on tropospheric climate is accounted for by using a SST development prescribed from observations. The SSTs are given as monthly mean values following the global sea ice and sea surface temperature (HadISST1) data set provided by the UK Met Office Hadley Centre (Rayner et al., 2003). The data are based on blended satellite and in situ observations. For the simulation, a linear interpolation based on the monthly mean values is applied. A few gaps in sea ice coverage appeared which were caused by the interpolation of the original data set to the model grid, e.g., a grid box in the Arctic region which is free of ice is surrounded by grid 
Table 2. Total intensity (solar constant, in $\mathrm{W} / \mathrm{m}^{2}$ ) and extraterrestrial fluxes (in phot $/ \mathrm{cm}^{2} \mathrm{~s}$ ) at the uppermost model level, as assumed in E39/C. The spectral intervals are given in $\mathrm{nm}$. The values for solar maximum represent values measured in the year 1991.

\begin{tabular}{lrrr}
\hline & $\begin{array}{r}\text { value in } \\
\text { solar minimum }\end{array}$ & $\begin{array}{r}\text { value in } \\
\text { solar maximum }\end{array}$ & $\begin{array}{r}\text { difference } \\
\text { [in \%] }\end{array}$ \\
\hline total intensity $\left[\mathrm{W} / \mathrm{m}^{2}\right]$ & 1365.00 & 1366.09 & 0.1 \\
\hline extra-terrestrial flux at $10 \mathrm{hPa}\left[\mathrm{phot} / \mathrm{cm}^{2} \mathrm{~s}\right]$ & & \\
\hline $178.8-202.0$ & $8.7990 \times 10^{12}$ & $9.6701 \times 10^{12}$ & 9.9 \\
$202.0-241.0$ & $1.7007 \times 10^{14}$ & $1.7704 \times 10^{14}$ & 4.1 \\
$241.0-289.9$ & $1.1179 \times 10^{15}$ & $1.1396 \times 10^{15}$ & 1.9 \\
$289.9-305.5$ & $1.2734 \times 10^{15}$ & $1.2786 \times 10^{15}$ & 0.4 \\
$305.5-313.5$ & $7.9740 \times 10^{14}$ & $8.0102 \times 10^{14}$ & 0.5 \\
$313.5-337.5$ & $3.3641 \times 10^{14}$ & $3.3660 \times 10^{14}$ & 0.1 \\
$337.5-422.5$ & $2.0640 \times 10^{16}$ & $2.0668 \times 10^{16}$ & 0.1 \\
$422.5-752.5$ & $1.2865 \times 10^{17}$ & $1.2865 \times 10^{17}$ & 0.0 \\
\hline
\end{tabular}

boxes which all contain ice. These obvious inconsistencies have been removed by hand.

Both, chemical and direct radiative effects of enhanced stratospheric aerosol abundance from large volcanic eruptions are considered. For the heterogeneous reactions covered in the chemistry module, sulphate aerosol surface area densities partly had to be approximated from observations as follows: The original data set consists of monthly and zonally averaged sulphate aerosol surface area densities (WMO, 2003). It was deduced from satellite-based extinction measurements (SAGE I, SAGE II, SAM II, and SME), as has been described in Jackman et al. (1996), using the methodology of Rosenfield et al. (1997). The Agung eruption in 1963 is not covered by this data set. As a remedy, the welldocumented years following the eruption of Mt. Pinatubo (1991-1994) have been adopted and associated with the period 1963-1966 with modifications based on published results to account for differences in total mass of sulphate aerosols in the stratosphere, in maximum height of the eruption plumes, and in the volcanoes' geographical location (e.g. Sato et al., 1993; Andronova et al., 1999; Robock, 2000). Above the maximum vertical extent of Agung's eruption plume the annual mean of 1979 has been incorporated. By 1979 the total mass of stratospheric sulphate aerosol had probably returned to its background value, being maintained by a permanent supply of tropospheric sulphur species (Junge et al., 1961; Mc Cormick et al., 1995). For the time periods 1960-1962 and 1968-1978 the annual mean of 1979 has been adopted, and for the period 1996-1999 the annual mean of 1995 has been used. Additionally, the data set has been interpolated linearly from 177 to 16 vertical levels and from 18 latitudes to 48 latitudes.
Eruption-related radiative heating is implemented in E39/C using pre-calculated monthly and zonal mean net heating rates. These rates are taken from a previous ECHAM4(T42)/L19 (L19 = 19 vertical layers) Pinatubo sensitivity experiment, which was forced by a realistic spacetime dependent aerosol distribution (Kirchner et al., 1999). Kirchner and colleagues forced their model by aerosol distributions and spectral radiative characteristics calculated applying SAGE II extinctions (same as mentioned above) and used effective radii retrieved by the Upper Atmosphere Research Satellite (UARS). We decided to use the precalculated heating rates after interpolating to the 39 layers of E39/C, as no significant difference was expected from a direct calculation in E39/C with both ECHAM4 versions using identical radiation codes. The data set provided by Kirchner et al. extends from July 1991 to April 1993. Thus, only part of the eruption-influenced time span was available, e.g., June 1991 (month of eruption) is missed. Therefore, for June 1991 the radiative forcing has been taken as $0.5 \times$ July 1991 values, and an exponential decay has been adopted in the period from May 1993 to July 1993. With regard to Agung and El Chichon, similar estimates of additional heating rates were not available due to the lack of solicited information of aerosol parameters. Considering the limited information about the pre-Pinatubo eruptions (see above) and as there are strong hints for similar temperature responses in the stratosphere (e.g. Labitzke, 1994), sets of heating rates for the Agung and El Chichon periods have been created with slight modifications to the horizontal structure of the radiative heating distributions. This approach is certainly a simplified one, but due to the lack of consistent information for the three volcanic eruptions this strategy seems to be reasonable as a first attempt.

The QBO is described based on zonal wind profiles measured near the equator. Radiosonde data from Canton Island (1953-1967), Gan/Maledives (1967-1975) and Singapore (1976-2000) have been used to develop a time series of monthly mean zonal winds at the equator (Naujokat, 1986; Labitzke et al., 2002). This data set covers the lower stratosphere up to $10 \mathrm{hPa}$. It is used to assimilate the QBO in E39/C, such that the QBO is synchronised with other external inter-annual variations prescribed in this experiment. For the assimilation it is assumed that the QBO is zonally symmetric, i.e., has little variation along a latitude band, and that it has a Gausian half width of about 12 degree latitude around the equator. The QBO is forced in $\mathrm{E} 39 / \mathrm{C}$ by a linear relaxation of the predicted zonal wind towards the constructed QBO time series, which follows the observed zonal wind profile (Giorgetta and Bengtsson, 1999). This assimilation is applied equatorwards of $20^{\circ}$ latitude from $90 \mathrm{hPa}$ up to the highest layer of the model centred at $10 \mathrm{hPa}$. The relaxation time scale has been set to 7 days within the QBO core domain. Outside of this core domain the time scale depends on latitude and pressure (Giorgetta and Bengtsson, 1999). Figure 1 shows the results of the assimilated monthly 

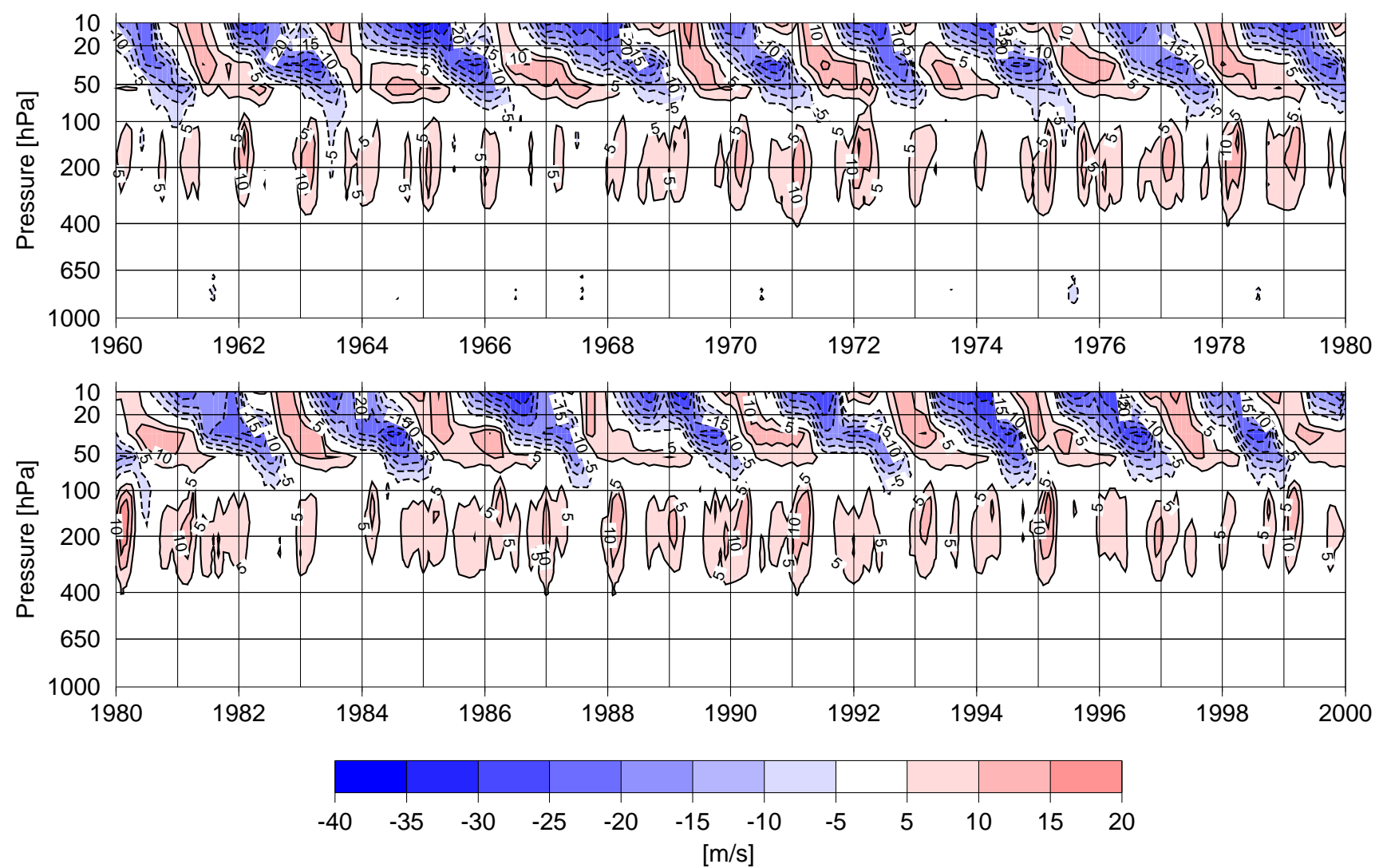

Fig. 1. Monthly mean zonal winds (in $\mathrm{m} / \mathrm{s}$ ) near the equator (zonal mean values) in the E39/C model simulation. Negative (positive) wind speed indicates easterly (westerly) wind.

mean zonal winds of the $\mathrm{E} 39 / \mathrm{C}$ run for the time period 1960 to 1999. The assimilated QBO compares well with the observed phase state and the observed amplitudes of the westerlies and easterlies (Giorgetta and Bengtsson, 1999, their Fig. 1).

The influence of the 11-year solar cycle on photolysis rates is parameterised according to the intensity of the $10.7 \mathrm{~cm}$ radiation of the sun (data available at: http://www.drao.nrc. $\mathrm{ca} /$ icarus/www/daily.html). Table 2 gives the values of the extra-terrestrial fluxes in different spectral intervals assumed for high (i.e., these values represent the year 1991) and low solar activity used at the upper boundary of E39/C. The 1991 solar maximum values are employed as reference values for the calculation of respective values for maximum solar activity of the other solar cycles which are considered in the transient run, i.e., 1958, 1969, and 1980. These values are scaled with the intensity of the $10.7 \mathrm{~cm}$ flux of the corresponding years. Photolysis rates are calculated in 8 spectral intervals (Landgraf and Crutzen, 1998). The spectral distribution of changes in extra-terrestrial flux is based on investigations presented by Lean et al. (1997). The ozone columns above the model top (centred at $10 \mathrm{hPa}$ ) are considered by a seasonally dependent climatology which is taken from HALOE observations. It must be mentioned that those climatological values represent an average of 6 years only and therefore do not consider changes due to the solar cycle. The impact of solar activity changes on short-wave radiative heating rates is prescribed based on changes of the solar constant (see Table 2). Short-wave radiative heating rates are considered in two spectral intervals (Morcrette, 1999; Fouquart and Bonnel, 1980), respecting continuum scattering, grey absorption, water vapour and uniformly mixed gases transmission functions and ozone transmission.

Continuously changing mixing ratios of the most relevant greenhouse gases $\left(\mathrm{CO}_{2}, \mathrm{~N}_{2} \mathrm{O}, \mathrm{CH}_{4}\right)$ are prescribed, $\mathrm{CO}_{2}$ for the entire model domain, the others at the Earth's surface according to Hein et al. (1997) and IPCC (2001; see Fig. 2). As mentioned above, for $\mathrm{CO}$ no long-term change is assumed. Changes in hydrocarbons are also not considered, except for methane. Neglecting these species and associated trends may lead to some underestimation of tropospheric ozone changes and an overestimate of $\mathrm{OH}$ values, but this should not affect significantly our conclusions of this paper. Natural and anthropogenic nitrogen oxide $\left(\mathrm{NO}_{\mathrm{x}}=\mathrm{NO}+\mathrm{NO}_{2}\right)$ emissions at the Earth's surface, and $\mathrm{NO}_{\mathrm{x}}$ emission from lightning and air traffic are considered. In the following a brief summary of the individual $\mathrm{NO}_{\mathrm{x}}$ emission sources and their temporal changes is given. 


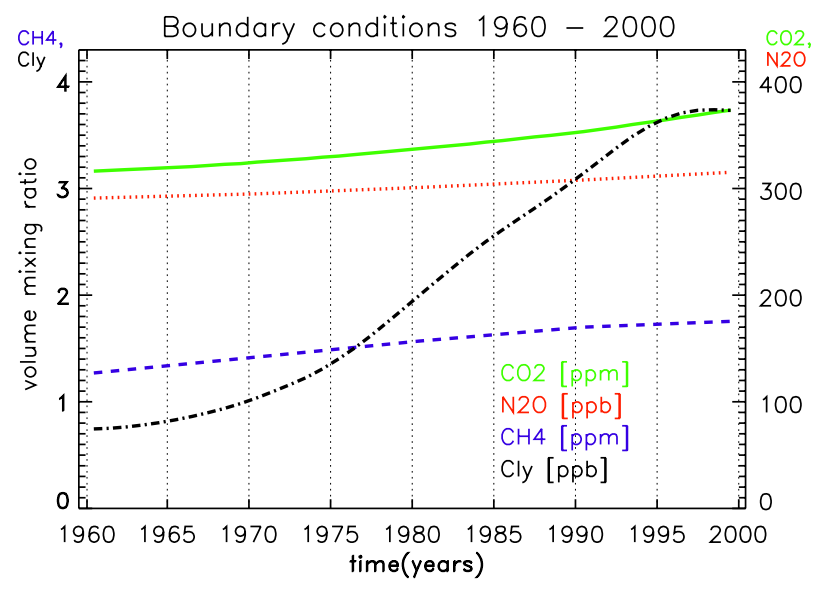

Fig. 2. Changes of mixing ratios of $\mathrm{CO}_{2}$ (in ppmv), $\mathrm{N}_{2} \mathrm{O}$ (in ppbv), $\mathrm{CH}_{4}$ (in ppmv), and $\mathrm{Cl}_{y}$ (in ppbv), as adopted in the transient simulation with $\mathrm{E} 39 / \mathrm{C}$.

The horizontal distribution of $\mathrm{NO}_{\mathrm{x}}$ emissions from industry is based on Benkovitz et al. (1996). Its temporal development has been adapted to match the Benkovitz et al. (1996), Hein et al. (2001), as well as the IPCC (2001) values. The increase of the emission rates from 1960 to 1999 are assumed to be piecewise constant, i.e., 2.5\%/year between 1960 and 1979, 1.5\%/year between 1980 and 1989, and 3.9\%/year between 1990 and 1999. This should represent the slowdown of emissions during the 1980s in Europe and the stronger increase during the 1990s mainly in Asia. The same geographic distribution is used for all years of the simulation with the global IPCC trend imposed. The different development in different global regions is neglected because reliable numbers were not accessible when the model run was started. This is certainly a constraint but should not have a substantial influence on the results discussed in this paper. Anthropogenic $\mathrm{NO}_{\mathrm{x}}$ emissions include those from surface transportation as an individual component (Matthes, 2003), which contributes approximately $30 \%$ to the total industry emissions (see also Matthes et al., 2005 ${ }^{1}$ ). Ship emissions have been removed from the global dataset (Benkovitz et al., 1996). Instead, a more sophisticated ship emission inventory with 1993 annual global $\mathrm{NO}_{\mathrm{x}}$ emissions of $3.08 \mathrm{Tg}(\mathrm{N})$ is used as the basic data set (Corbett et al., 1999). Trend estimates of $\mathrm{NO}_{\mathrm{x}}$ emissions from international shipping for the time period 1960 to 2000 have been adopted from Eyring et al. (2005a). Based on these assumptions, the annual global $\mathrm{NO}_{\mathrm{x}}$ emissions from ships for the years 1960 to 1999 amount to $1.17 \operatorname{Tg}(\mathrm{N})$ and $3.28 \operatorname{Tg}(\mathrm{N})$, respectively. Aircraft $\mathrm{NO}_{\mathrm{x}}$ emissions are based on a data set representing 1992 (Schmitt and Brunner, 1997). Trends previous to 1992 have been ex-

\footnotetext{
${ }^{1}$ Matthes, S., Grewe, V., Sausen, R., and Roelofs, G.-J.: Global impact of road traffic emissions on the chemical composition of the atmosphere, Atmos. Chem. Phys. Disscuss., submitted, 2005.
}

trapolated using IPCC (1999). For the period 1992 to 1999 an exponential interpolation has been applied. The aircraft $\mathrm{NO}_{\mathrm{x}}$ emissions for the years 1960 to 1999 amount to $0.10 \operatorname{Tg}(\mathrm{N})$ and $0.71 \operatorname{Tg}(\mathrm{N})$, respectively.

Nitrogen oxide emissions from biomass burning are based on Hao et al. (1990) and have been revised using ATSR fire counts (David Lee, pers. comm., 2004). The trend rates used are based on estimates presented in Chapter 4 of IPCC (1999): An increase of $\mathrm{NO}_{\mathrm{x}}$ emissions from biomass burning of 7\% has been specified for the years between 1992 and 2015 which results in a rate of approximately $0.3 \% / y e a r$. This rate is used in the E39/C transient simulation and it leads to an increase of $13 \%$ between 1960 and 1999. Global $\mathrm{NO}_{\mathrm{x}}$ soil emissions by micro-biological production are assumed to be constant over the four decades of the transient simulation. They are taken from Yienger and Levy (1995). As mentioned above, lightning $\mathrm{NO}_{\mathrm{x}}$ emissions are calculated interactively, based on the parameterised mean mass flux in the updraft of deep convective clouds (see previous section), resulting in a mean annual emission of $5.16 \mathrm{Tg}(\mathrm{N})$. The interannual variability ranges between 4.81 and $5.42 \mathrm{Tg}(\mathrm{N}) / \mathrm{a}$ and the seasonal cycle varies with $\pm 14 \%$. We anticipate that no systematic trend of lightning $\mathrm{NO}_{\mathrm{x}}$ emissions is found over the 40-year transient simulation.

To take into account exchange processes from the upper stratosphere, upper boundary conditions are adopted for the two families $\mathrm{ClX}$ and $\mathrm{NO}_{\mathrm{y}}$ at $10 \mathrm{hPa}$ $\left(\mathrm{ClX}=\mathrm{HCl}+\mathrm{ClONO}_{2}+\mathrm{ClO}_{\mathrm{x}}\right.$, $\mathrm{ClO}_{\mathrm{x}}=\mathrm{Cl}+\mathrm{ClO}+\mathrm{ClOH}+2 \cdot \mathrm{Cl}_{2} \mathrm{O}_{2}+2 \cdot \mathrm{Cl}_{2}$, $\mathrm{NO}_{\mathrm{y}}=\mathrm{NO}_{\mathrm{x}}+\mathrm{N}+\mathrm{NO}_{3}+2 \cdot \mathrm{N}_{2} \mathrm{O}_{5}+\mathrm{HNO}_{4}+\mathrm{HNO}_{3}$ ).

They largely determine lower stratospheric nitrogen oxide and chlorine concentrations. Monthly mean concentrations are taken from results of the two-dimensional (2-D) middle atmosphere model by Brühl and Crutzen (1993), which also considers effects of the 11-year solar cycle. For example, the $\mathrm{NO}_{\mathrm{y}}$ values prescribed at the model's upper boundary fluctuate according to solar activity. Since CFCs are not explicitly transported by E39/C, they are included based on results derived from the 2-D model (depending on latitude and altitude), and serve as a source for total chlorine $\left(\mathrm{Cl}_{\mathrm{y}}\right)$ by photolysis within the model domain. The development of CFC concentrations is prescribed in agreement with most recent assumptions (WMO, 2003). Stratospheric $\mathrm{Cl}_{\mathrm{y}}$ has been calculated as a sum of the simulated $\mathrm{ClO}_{\mathrm{x}}, \mathrm{ClONO}_{2}$, $\mathrm{HCl}$ fields, and chlorine from the prescribed $\mathrm{CFC}$ fields (see Fig. 2). Its temporal evolution reflects the observed development (WMO, 2003, their Figs. 1-7).

\section{Long-term trends}

In this section climatic variability and trends of key parameters will be presented and discussed with respect to corresponding observations. 

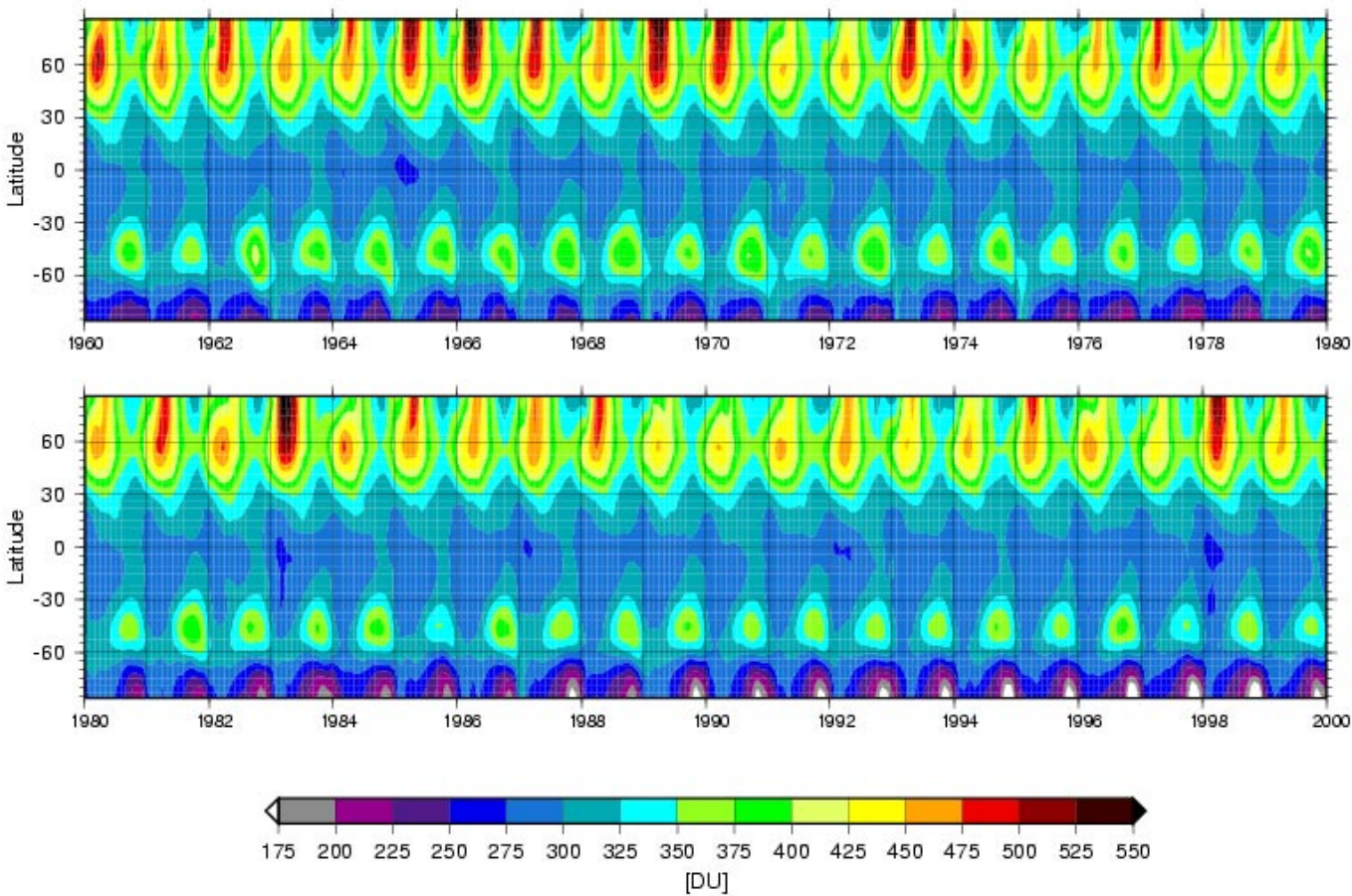

Fig. 3. Development of monthly mean total ozone between 1960 and 1999, as calculated with E39/C. The zonal mean values are given in Dobson Units (DU).

\subsection{Ozone}

Figure 3 shows the development of monthly and zonal mean total ozone for the whole simulation period. It indicates the well-known features, e.g., highest ozone values in northern spring time which is highly variable from year-to-year, low ozone values in the tropics with a small seasonal cycle and little interannual variability, a relative ozone maximum in mid-latitudes of the Southern Hemisphere in late winter/early spring, and a minimum ozone column above the south polar region in the same period. The ozone hole appears for the first time in the year 1982 in E39/C, which is in agreement with observations (Chubachi, 1985; Farman et al., 1985). An additional interesting feature is the absence of total ozone values above $475 \mathrm{DU}$ in the Northern Hemisphere during the late 1980s and the first half of the 1990s. This indicates a period of at least six years without distinct midwinter warmings of the stratosphere. There is no other comparable episode in the 40-year simulation. This agrees with the evolution of the real atmosphere, where northern winters from $1989 / 1990$ to $1996 / 1997$ show no major stratospheric warming events (e.g. Naujokat and Pawson, 1996; Naujokat et al., 1997; Pawson and Naujokat, 1999) resulting in significant springtime ozone losses during these years (e.g. Rex et al., 2004).

For a closer insight into regional and temporal patterns in the interannual variability of ozone changes, Fig. 4 shows total ozone anomalies for the whole model simulation with respect to mean values based on the years 1964 to 1980 . The features discussed above can easily be identified again, especially that ozone depletion begins at high latitudes of the Southern Hemisphere and that the reduction of the ozone layer occurs later in both, the Northern Hemisphere and the tropical region. But there are also some additional eyecatching features: For example, as identified in observations (e.g. Bojkov and Fioletov, 1995), the ozone holes in the years 1986 and 1988 are clearly smaller than in the respective year before. A closer inspection of the dynamics of the polar vortices in E39/C during these years indicate in both cases that the vortex is less stable and displaced from the polar region towards lower latitudes, which is very similar to the observed dynamical behaviour of the polar vortices in 1986 and 1988. There are a number of other interesting similarities in midlatitudes of the Southern Hemisphere, i.e., modelled positive and negative ozone anomalies which nicely match observations, in particular in 1985, 1989, 1991, 1992, and 1996 (see Bojkov and Fioletov, 1995, their Plate 1). A process related discussion about possible reasons for these consistencies with observations will be given in the next section. Looking into the tropics, there is distinct variability clearly reflecting the QBO signal; this is discussed in more detail in Sect. 4.2.

Before looking more closely at the long-term variability and changes (trends) calculated by the model, we take a look at the systematic bias of total ozone in E39/C. Figures 5a 

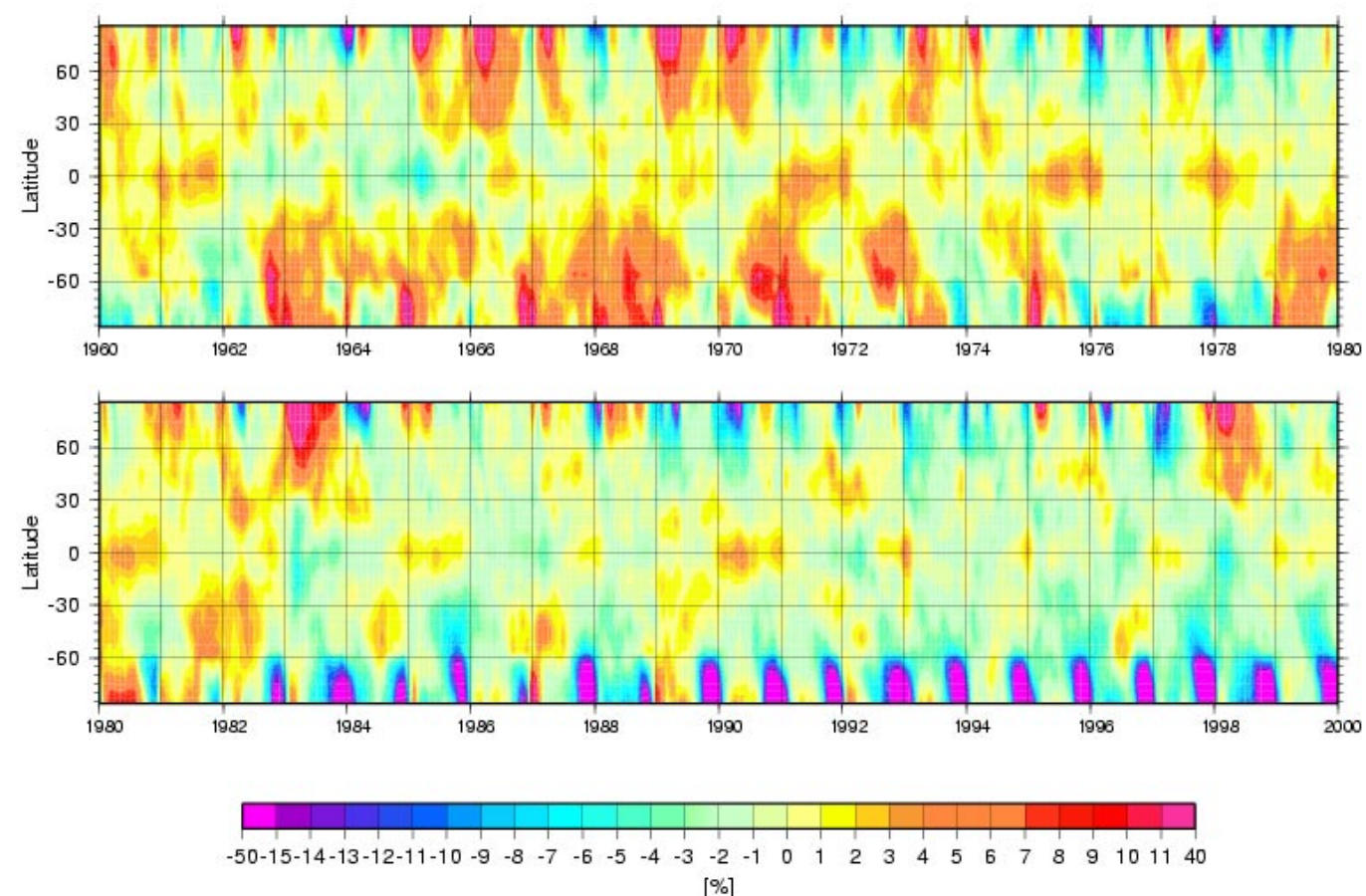

Fig. 4. Anomalies of total ozone relative to associated mean values derived for the period between 1964 and 1980 . Positive (negative) values (in \%) indicate more (less) ozone with regards to the reference period.

and $5 \mathrm{~b}$ show 20-year mean climatological total ozone values derived from the E39/C simulation, i.e., the 1960s and 1970s, and the 1980s and 1990s. The climatology derived from measurements of the TOMS instrument for the years 1980 to 1999 is displayed in Fig. 5c. A comparison of Figs. $5 b$ and $5 c$ indicates that E39/C is able to reproduce the main features (e.g., regional distribution, seasonal cycle) in qualitative agreement with TOMS observations. In the Northern Hemisphere and the tropics, the model calculates total ozone values which are about 10 to $15 \%$ higher than the values derived from TOMS. These model results confirm the findings of the E39/C time-slice experiments (e.g. Hein et al., 2001). However, in the Southern Hemisphere the model shows an improved behaviour with respect to former studies with E39/C: The absolute total ozone values are in overall agreement with TOMS, merely the ozone hole season in E39/C lasts slightly longer and the mid-latitude ozone maximum is somewhat higher. This model improvement can partly be attributed to the fact that large SZAs are now considered for the calculation of photolysis rates which has a clear impact on the model behaviour, particularly in the Southern Hemisphere (Lamago et al., 2003).

Figure $5 \mathrm{~d}$ displays the differences between the two E39/C climatologies affected by the ozone hole (1980-1999; Fig. 5b) and the preceding era (1960-1979; Fig. 5a). Since the 1960s and 1970s represent a climatological mean state of an almost unperturbed episode, this climatology can be taken as a basis to derive trends from 1980 onwards. As an- ticipated, largest changes are found in the south polar region during spring time, where 60 DU less ozone is calculated in the second half of the transient simulation compared with the first half. This amounts to an ozone reduction of about $20 \%$ per decade. Especially in the 1990s, ozone decreases steadily with more than $40 \%$ less ozone at the end of the century compared to 1980 . These estimates agree well with numbers derived from observations. For example, based on TOMS-data for the years between 1978 and 1994, Mc Peters et al. (1996) estimated an ozone loss of $20 \%$ /decade.

Also in the Northern Hemisphere, the trend pattern and absolute numbers agree with analyses from measurements: Mc Peters et al. found an ozone reduction in northern spring of about $6 \% /$ decade. The model shows a decrease of about $25 \mathrm{DU}$ (Fig. 5d), which relates to a trend of about $5 \%$ per decade. A small increase (less than 7 DU) in total ozone is simulated by E39/C in northern summer. It is caused by an increase of tropospheric ozone concentration whereas at the same time no clear change is simulated in the lower stratosphere (see Fig. 6b). The vertical ozone distribution (Fig. 6a) and its seasonal changes are very similar to results derived from E39/C time-slice experiments (e.g. Hein et al., 2001) which are in reasonable agreement with observations (e.g. Fortuin and Kelder, 1998). The simulated ozone changes throughout the four decades are almost everywhere statistically significant: Ozone mixing ratios have increased during equinox (MAM, SON) in the middle troposphere of the Northern Hemisphere by more than 10 ppbv, whereas in the 
(a)

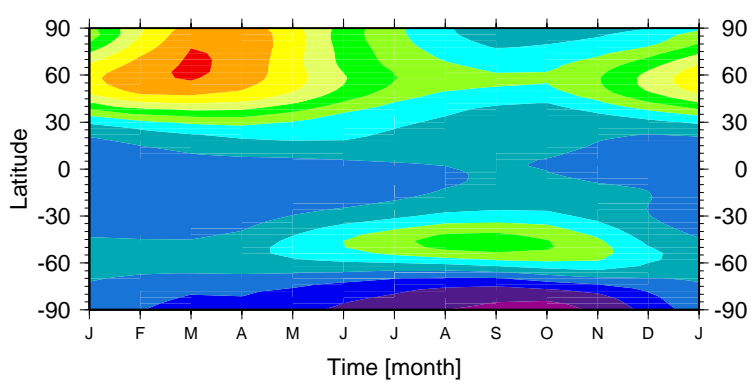

175200225250275300325350375400425450475500525550 [DU]

(c)

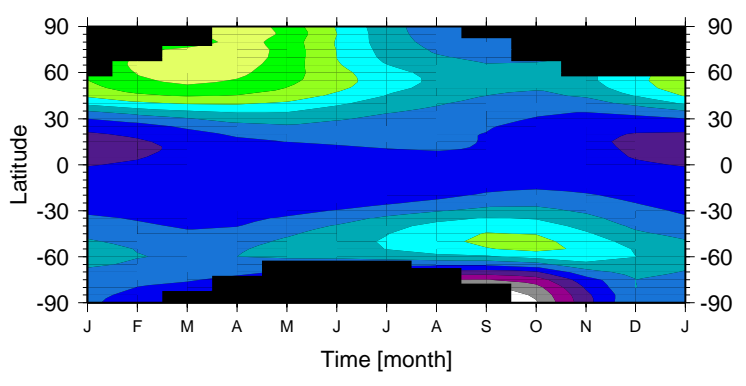

175200225250275300325350375400425450475500525550 [DU] (b)

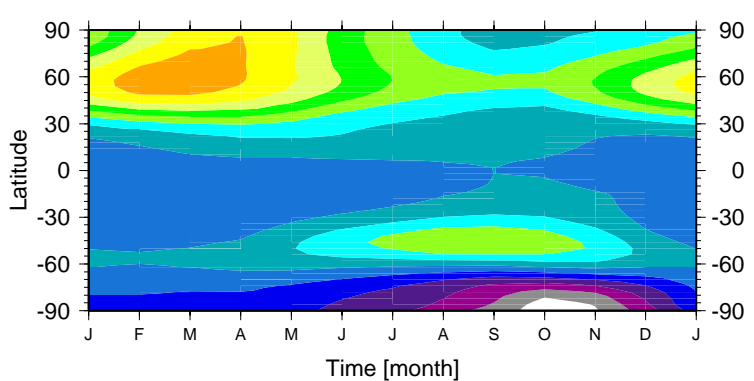

175200225250275300325350375400425450475500525550 [DU]

(d)

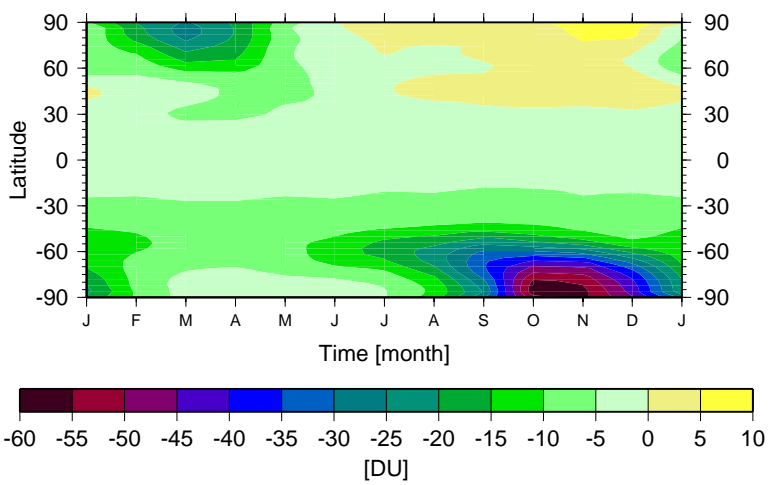

Fig. 5. Climatologies of total ozone derived from E39/C for the periods 1960 to 1979 (a), 1980 to 1999 (b), and from TOMS measurements during the years from 1980 to 1999 (c). Differences between the two E39/C climatologies are displayed in (d), where positive (negative) values indicate more (less) ozone in second half of the 40-year transient simulation. Given values are in DU.

lower stratosphere a general decrease is evident, in particular in the polar Southern Hemisphere spring time (SON). The increase of tropospheric ozone mixing ratios is due to the increased $\mathrm{NO}_{\mathrm{x}}$ emissions (e.g. Grewe et al., 2001b) whereas stratospheric ozone depletion is a consequence of increased halogen loading and temperature decrease in the stratosphere due to an increased abundance of GHGs (e.g. Schnadt et al., 2002).

\subsection{Temperature and zonal wind}

Climatologies of temperature and zonal mean wind fields for the 1960s and their changes throughout the four decades, as simulated by E39/C, are displayed in Figs. 7 and 8. The mean fields for the 1960s (Figs. 7a and 8a) are satisfactorily reproduced compared with NCEP re-analysis data (not shown) as well as the climatological mean values for the 1990s (see also Pawson et al., 2000). Sub-tropical and polar night jets are clearly distinguishable, i.e., a transition zone with reduced wind speed is found in both hemispheres for all seasons. A continuous model problem arises in the Southern Hemisphere winter and spring months, where E39/C is calculating too low temperatures in the entire polar lower stratosphere. Therefore, the climatological mean polar vortex is too strong and stable (Fig. 8a, see also Hein et al., 2001; Austin et al., 2003). Another discrepancy has been identified in the zonal mean stratospheric wind fields in the summer hemispheres. The summer vortices in both hemispheres are slightly shifted towards the tropics, a wind reversal in upper model layers at higher latitudes is missed. No easterly winds are simulated poleward of $55^{\circ} \mathrm{S}$ in the Southern Hemisphere (DJF) and in the Northern Hemisphere (JJA), the calculated easterlies at polar latitudes are too weak. The structure of temperature changes between the 1960s and 1990s (i.e., increase of tropospheric temperature, decrease of stratospheric temperature) partly arises from the increase in greenhouse gas concentrations, in the polar lower stratosphere it mostly reflects the decrease of ozone (Fig. 7b). Strongest temperature decrease is seen in the Southern Hemisphere polar lower stratosphere in SON (up to $10 \mathrm{~K}$ at $30 \mathrm{hPa}$ ) and DJF (up to $6 \mathrm{~K}$ at around $70 \mathrm{hPa}$ ), the time during and after the appearance of the ozone hole, which is in good agreement with assessments derived from observations (e.g. Randel and Wu, 1999). A statistically significant temperature increase of more than $1 \mathrm{~K}$ is found in the (sub-)tropical upper troposphere whereas a (non significant) cooling is calculated in the lower tropical stratosphere. The latter finding is in qualitative agreement with 

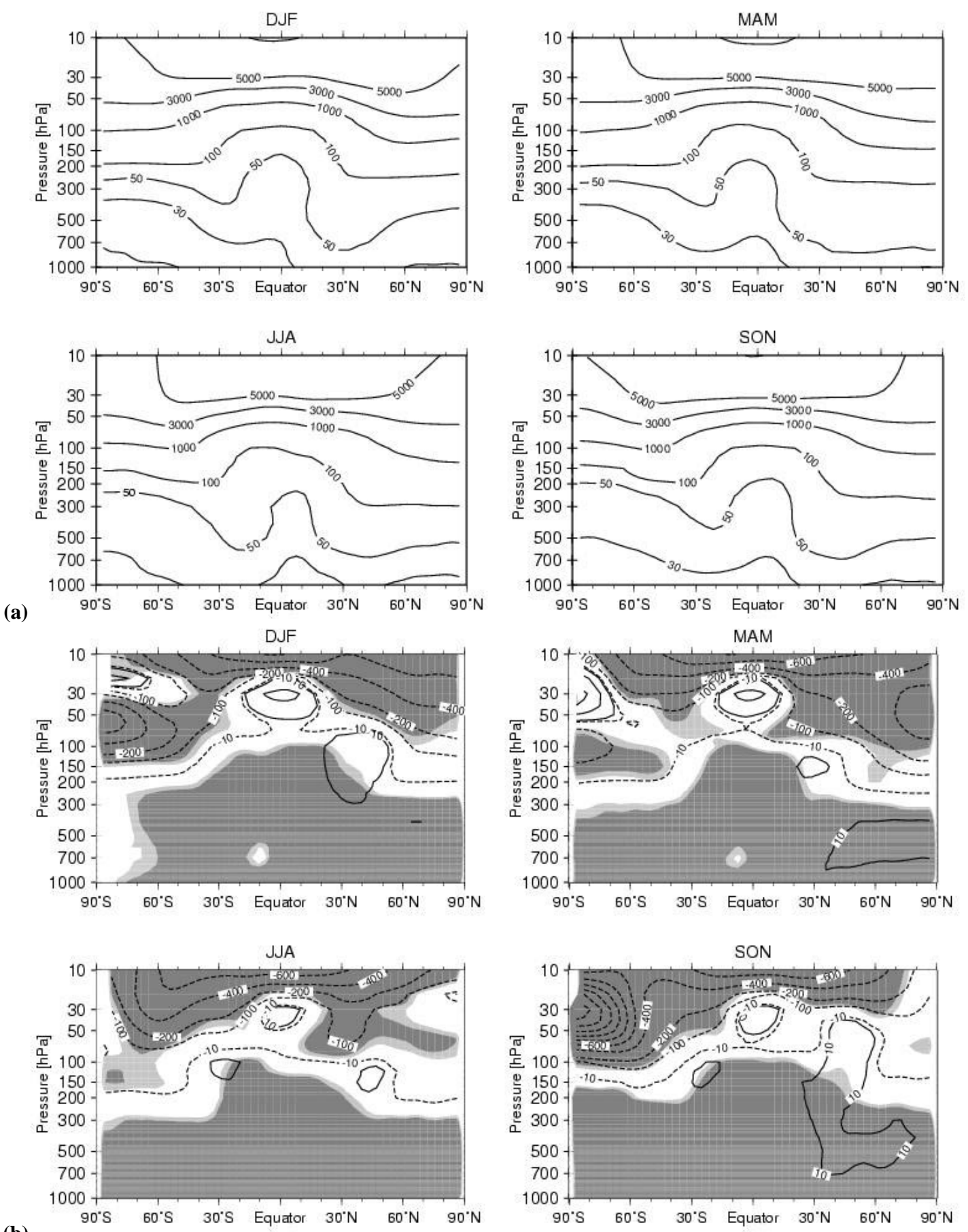

Fig. 6. (a) Seasonal mean values of zonal mean ozone mixing ratios derived from E39/C transient simulation for the 1960s (1960 to 1969). (b) Differences calculated between mean values derived for the 1960s and corresponding values for the 1990s. Positive (negative) values indicate more (less) ozone in the 1990s. Light (dark) shading indicates regions in which differences are statistically significant at the $95 \%$ (99\%) level (t-test). Units are in ppbv.

analyses of observations which also indicate a cooling trend with numbers ranging from 0.3 to $1.4 \mathrm{~K}$ per decade (e.g. WMO, 1999). The picture is rather unclear in the tropical tropopause region. For example, temperature trends derived from observations estimated at $100 \mathrm{hPa}(\mathrm{WMO}, 1999)$ range from +0.3 to $-0.5 \mathrm{~K}$. Certainly, this is a difficult region to 

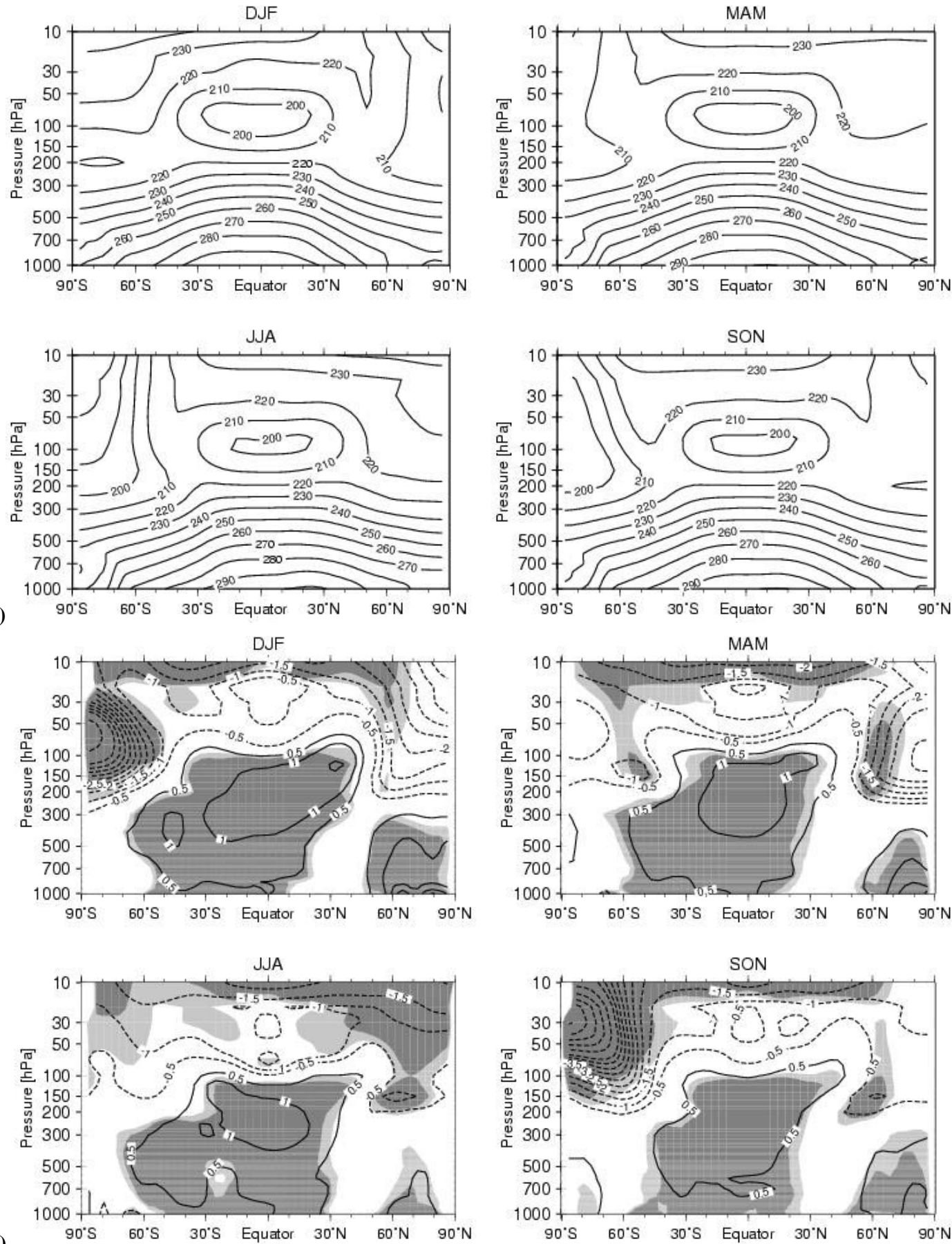

Fig. 7. Same as in Fig. 6, but for temperature. Positive (negative) values indicate higher (lower) temperature in the 1990s. Units are in K. The interval of contour lines is $0.5 \mathrm{~K}$, minimum values in the southern polar stratosphere are $-5.5 \mathrm{~K}$ in DJF and $-7.0 \mathrm{~K}$ in SON.

obtain a clear trend signal, because it is the transition layer with a warming below and a cooling above. As many other models, E39/C simulates a warming in the upper troposphere which maximises at $250 \mathrm{hPa}$, but this is not in agreement with radiosonde temperature data which indicate a cooling (e.g.
Parker et al., 1997). Long-term temperature changes at middle and higher latitudes of the Northern Hemisphere middle troposphere $(500 \mathrm{hPa})$ derived from E39/C (Fig. 7b) vary between $+0.5 \mathrm{~K}$ (JJA) and +1.0 K (DJF), which is less than detected at the Meteorological Observatory Hohenpeissenberg 

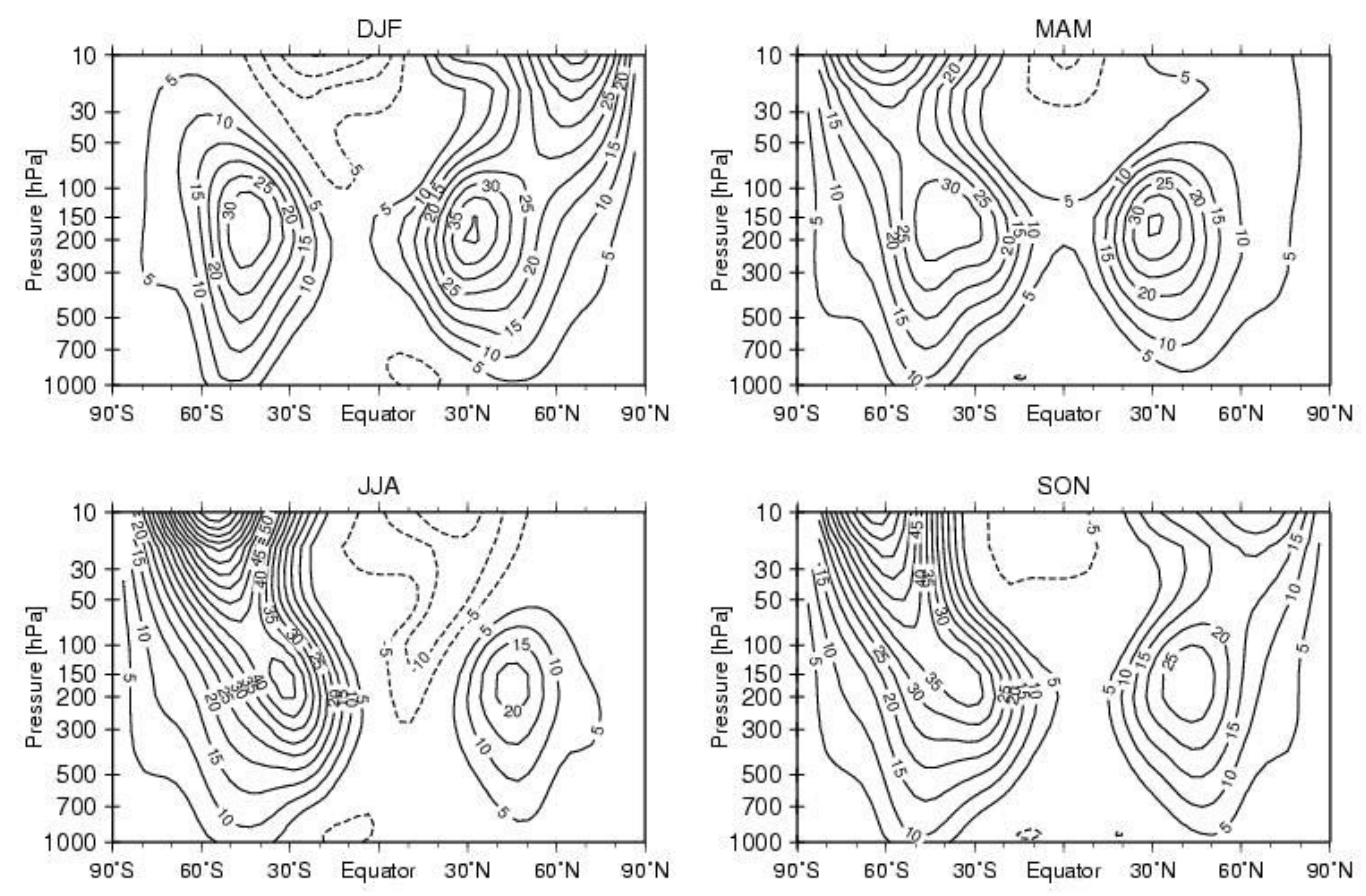

(a)
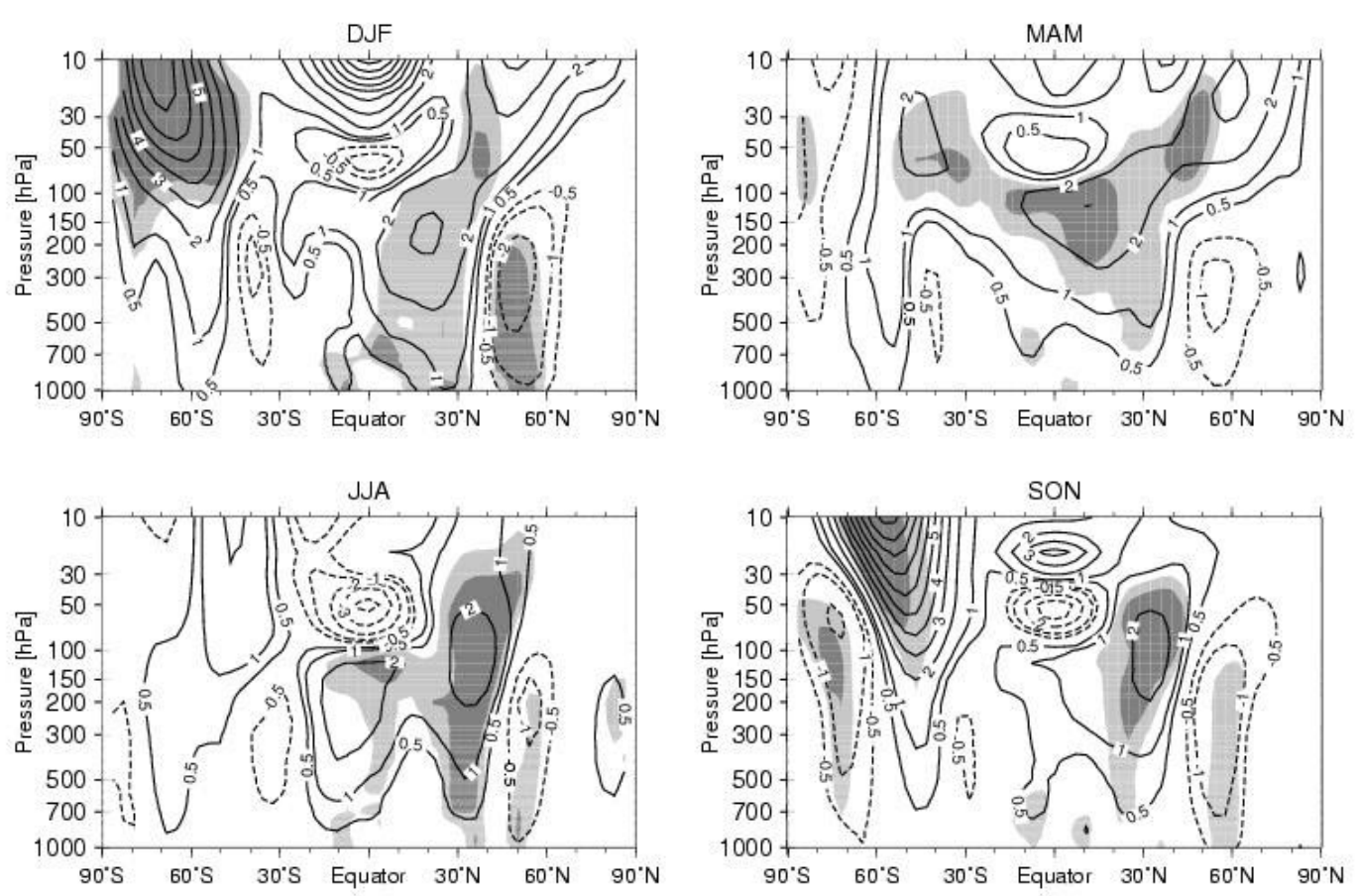

Fig. 8. Same as in Fig. 6, but for zonal wind. Positive (negative) values indicate higher (lower) wind speed in the 1990s. Units are in $\mathrm{m} / \mathrm{s}$. The interval of contour lines is $1 \mathrm{~m} / \mathrm{s}$ plus the 0.5 and -0.5 contour lines, maximum values in the southern stratosphere are $7 \mathrm{~m} / \mathrm{s}$ in DJF and $10 \mathrm{~m} / \mathrm{s}$ in SON.

(MOHp), station of the German Weather Service $\left(47.8^{\circ} \mathrm{N}\right.$, $11^{\circ} \mathrm{E}$ ) where an increase of $0.7 \pm 0.3 \mathrm{~K}$ per decade has been found since 1967 (Steinbrecht et al., 1998). One reason for this might be that many tropospheric ozone precursors including their trends are not considered in the E39/C simula- tion. In general, the long-term temperature changes derived from the E39/C transient model simulation confirm recent estimates from E39/C time-slice experiments (i.e. 1980 and 1990 conditions) presented also in Shine et al. (2003). 

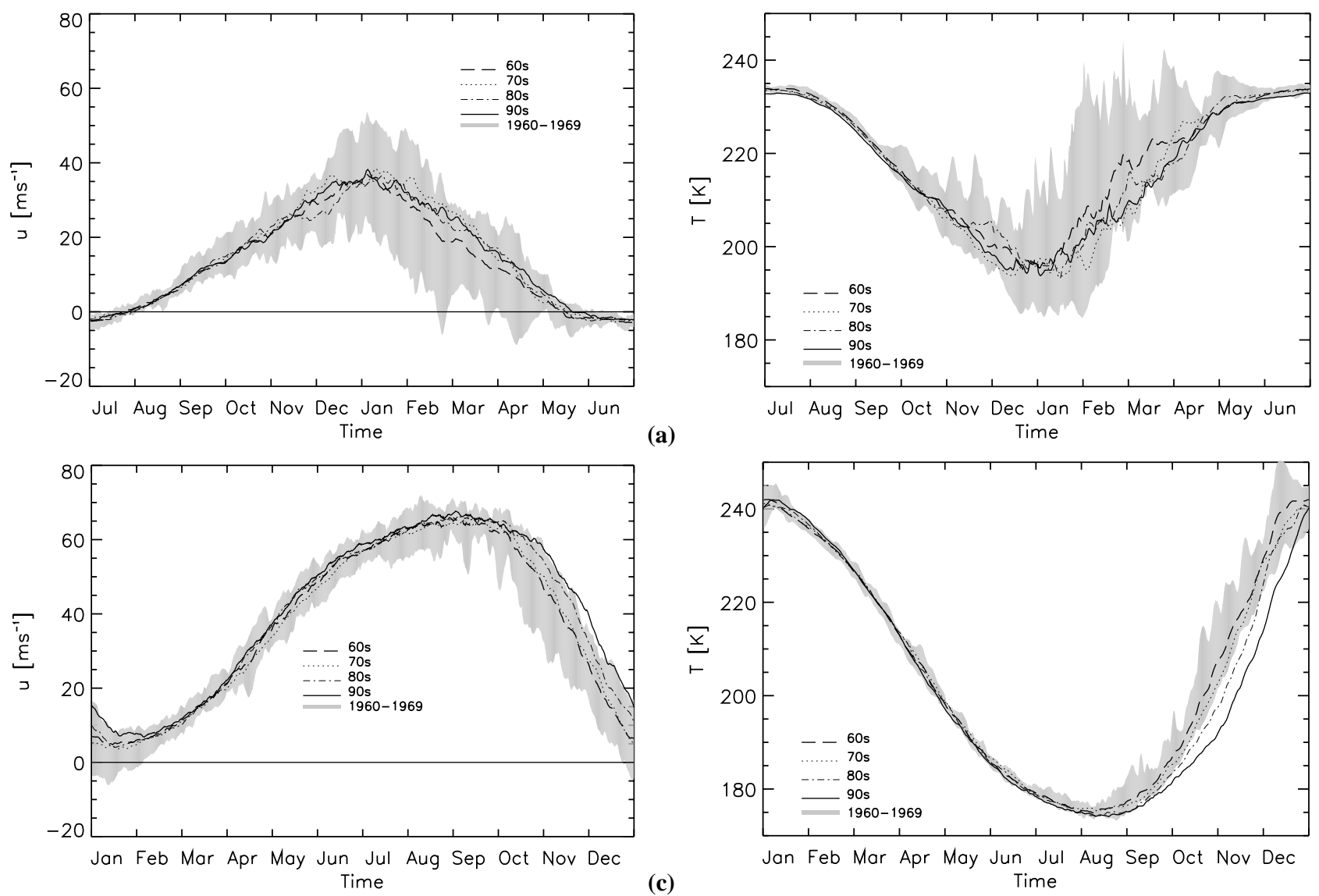

(a)

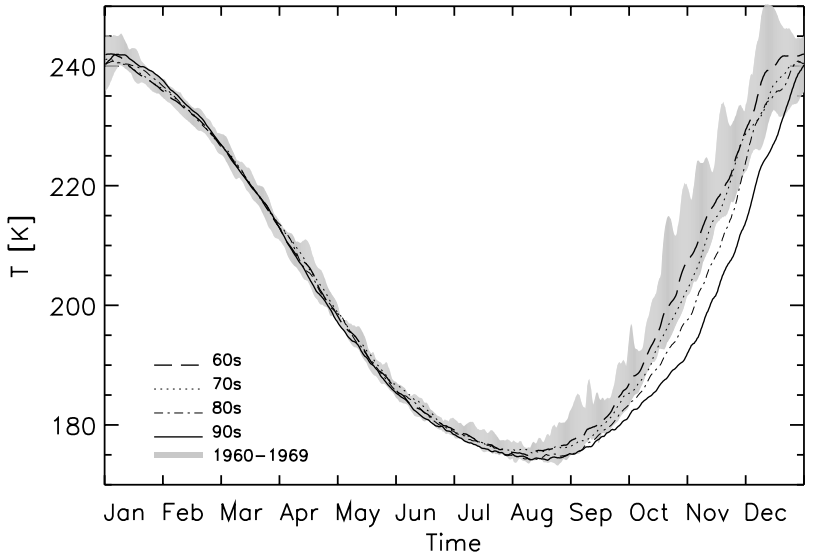

(b)

Fig. 9. Climatological mean curves of the annual cycle of the zonal wind (in $\mathrm{m} / \mathrm{s}$ ) at $60^{\circ} \mathrm{N}$ (a) and $60^{\circ} \mathrm{S}$ (c) at $30 \mathrm{hPa}$, and of the zonal mean temperature (in K) at $80^{\circ} \mathrm{N}$ (b) and $80^{\circ} \mathrm{S}$ (d) at $30 \mathrm{hPa}$. Different lines indicate decadal mean values of the four decades, i.e. the $1960 \mathrm{~s}$, 1970s, 1980s, and 1990s. The shaded areas show the range of minimum and maximum values found within the 1960s.

Corresponding changes of the zonal mean wind field are shown in Fig. 8b. The statistically significant increase of the zonal mean wind speed of up to $6 \mathrm{~m} / \mathrm{s}$ in the Southern Hemisphere lower stratosphere during spring (SON) and summer months (DJF) reflects the ozone hole formation and the corresponding decrease of polar stratospheric temperatures. Another systematic change pattern, which is obvious throughout all seasons, is found at mid-latitudes of the Northern Hemisphere (the pattern is obvious though less distinct in the Southern Hemisphere, as well). Here, the temperature change in the upper troposphere/lower stratosphere intensifies the zonal wind due to the thermal wind equation. This results in a more intense tropospheric jet stream in DJF and MAM, and tends to shift the jet stream to lower latitudes in JJA and SON. This is accompanied by a warming of the Arctic lower troposphere and a reduction of the horizontal temperature gradient at lower altitudes, resulting in a reduction of the zonal mean wind at around $50^{\circ}$ to $60^{\circ} \mathrm{N}$. The strengthening of the tropospheric jet is consistent with observations, however the weakening of the westerly zonal flow near the surface at northern latitudes from about $50^{\circ}$ to $60^{\circ}$ is not (e.g. Shindell et al., 2001).
To display dynamical changes of the polar vortices during the 40 model years, an analysis of zonal mean temperature and zonal wind is presented in the style of the NCEP analyses (see NCEP web-page: http://code916.gsfc.nasa.gov/ Data-services/met/). Figure 9 shows climatological mean curves of the annual cycle of the zonal wind at $60^{\circ} \mathrm{N}$ and $\mathrm{S}$ at $30 \mathrm{hPa}$ (Figs. 9a and c) and of the zonal mean temperature at $80^{\circ} \mathrm{N}$ and $\mathrm{S}$ at $30 \mathrm{hPa}$ (Figs. $9 \mathrm{~b}$ and d). The lines represent mean values for the four decades covered by the transient simulation, the shaded area denotes the minimum and maximum values reached during the 1960s of the model. Similar to the results presented in Hein et al. (2001), the model again shows its ability to reproduce hemispheric differences of dynamical variability changes. While the annual cycle is well captured in both hemispheres, and the mean values in the Northern Hemisphere agree well with respective analyses derived from observations, the model shows again deficiencies in the Southern Hemisphere which are related to the cold bias (see discussion above). With regards to the dynamical variability of the Northern Hemisphere during winter and spring, E39/C shows reduced interannual variability in early winter. Nevertheless, E39/C is able to reproduce stratospheric 
warmings in mid and late winter, but the number of major events is smaller than observed. In the Northern Hemisphere the climatological mean values for the four decades do not indicate systematic changes (mainly due to the high dynamical variability), which is supported by analyses of observations (e.g. Labitzke and Naujokat, 2000). In the Southern Hemisphere the lower stratosphere changes steadily towards more stable polar vortices and colder conditions in late winter and early spring. The lifetime (persistence) of the polar vortex has been prolonged by about three weeks, as the comparison of the results of the 1960s with those of the 1990s shows. This is in good agreement with an estimate presented by Zhou et al. (2000) who carried out their analysis on 19 years (1979-1998) of NCEP/NCAR reanalysis data and found that the Southern Hemisphere polar vortex has last about two weeks longer in the 1990s than in the early 1980s.

\subsection{Tropopause and water vapour}

Lower stratospheric water vapour trends may give a substantial contribution to the total radiative forcing of trace gas changes in the recent past (e.g. Rosenlof et al., 2001; Forster and Shine, 2002). However, results from time series analysis of the few available observed data (e.g. Oltmans et al., 2000; Rosenlof et al., 2001; Randel et al., 2004) of stratospheric water vapour do not produce a uniform picture of the magnitude and even the sign of a respective trend. A possible feedback chain driving stratospheric water vapour trends involves trends in tropopause height (e.g. Steinbrecht et al., 2001; Santer et al., 2003) and related tropopause temperature, which at least in the tropics may control changes in the water vapour penetration from the troposphere into the stratosphere (Zhou et al., 2001). While in the present paper we will not investigate in detail the mechanisms responsible for long-term changes of water vapour concentrations in the lower stratosphere (a paper on this individual subject will be prepared later), we will give a brief overview of the overall trend simulated in the transient simulation.

The changes of the thermal tropopause pressure are given in Fig. 10a. Whereas no obvious systematic changes (trends) are seen in the first two decades of the simulation, model results indicate a gradual change in tropopause height after about 1980. In both hemispheres, E39/C simulates a decrease (increase) of tropopause pressure (height) poleward of around $50^{\circ}$. The subtropical regions show an increase (decrease) of tropopause pressure (height). There appears to be no uniform trend throughout the 40-year simulation in the tropics. The major volcanic eruptions included in the transient simulation lead to a temporary increase of tropopause pressure due to tropospheric cooling. Changes in tropopause temperature (not shown) are directly related to the variability of the tropopause height: An increase (decrease) of tropopause height goes along with a decrease (increase) of tropopause temperature. A comparison with an analysis of tropopause height changes at $\mathrm{MOHp}, 47.8^{\circ} \mathrm{N}$ (Steinbrecht et al., 1998, 2001) shows a qualitative agreement, i.e., a more or less steady increase of tropopause height in February during the last 30 years. However, the model underestimates the rise in tropopause height compared to the estimates by Steinbrecht et al. (2001). Whereas Steinbrecht et al. finds an increase of $125 \mathrm{~m} / \mathrm{dec}$ ade for the station MOHp, E39/C calculates only about $+80 \mathrm{~m} /$ decade for the corresponding model grid point. A possible explanation for the rise of tropopause height might be identified in the warming of the troposphere and accompanying cooling of the stratosphere (Steinbrecht et al., 2001). If this is the case, the difference between model results and observations might be explained by the fact, that the tropospheric warming in the model at Northern Hemisphere mid-latitudes is smaller than observed (see discussion above).

Figure $10 \mathrm{~b}$ depicts the changes of water vapour mixing ratio at the thermal tropopause during the 40 year model simulation. A uniform trend is obvious only in the subtropical region, where water vapour mixing ratios are higher in the late 1980s and throughout the 1990s. Long-term changes are not uniform in the tropics, and neither at middle and high latitudes of both hemispheres. As discussed before, the volcanic eruptions involve characteristic signatures (see also below).

The general distribution of the pattern change in the lower stratosphere is equal to that at the tropopause. E39/C results, which allow a comparison with measurements of the Boulder frost point hygrometer and corresponding HALOE data discussed in Randel et al. (2004) (their Fig. 8a), are presented in Fig. 11 for the lower stratosphere $(80 \mathrm{hPa})$. The figure shows not only the results at $40^{\circ} \mathrm{N}$, but also at $40^{\circ} \mathrm{S}$, since the temporal development is very similar.

A comparison between the measurement time series of stratospheric water vapour over Boulder (Oltmans et al., 2000) and the respective model data for the period after 1979 indicates a systematic model error with respect to the absolute concentration, but good agreement with respect to the observed trend during these two decades (Stenke and Grewe, 2005). While the simulated stratospheric water vapour distribution was significantly improved by including methane oxidation (e.g. Hein et al., 2001), it has also been established that the Boulder trend, as well as other observed trends during the 1990s are too strong to be explained by methane oxidation alone (Rosenlof, 2002). Recently, Joshi and Shine (2003) have proposed that part of the observed long-term water vapour trend may be explained by the observed series of volcanic eruptions, provided that the stratospheric residence time of water vapour is in the order of 5 to 10 years and, thus, considerably longer than the residence time of the volcanic aerosols. Our model simulations do not reproduce this behaviour, as they indicate a memory of little more than 4 years at about $25 \mathrm{~km}$ height (Fig. 11).

Interestingly, E39/C simulates no positive trend in lower stratospheric water vapour mixing ratios in the years before 1980. On the contrary, a negative trend is found in the 1960s. A further discussion about possible reasons for this model 

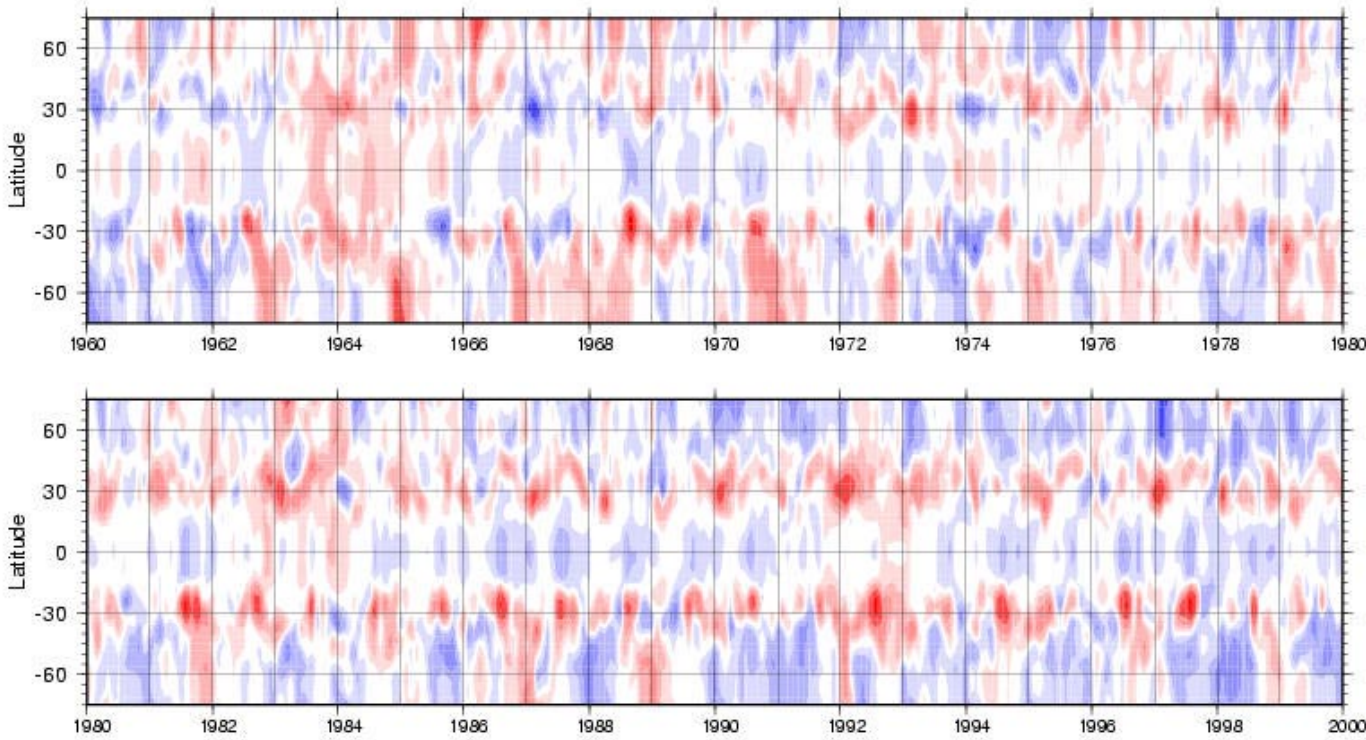

(a)
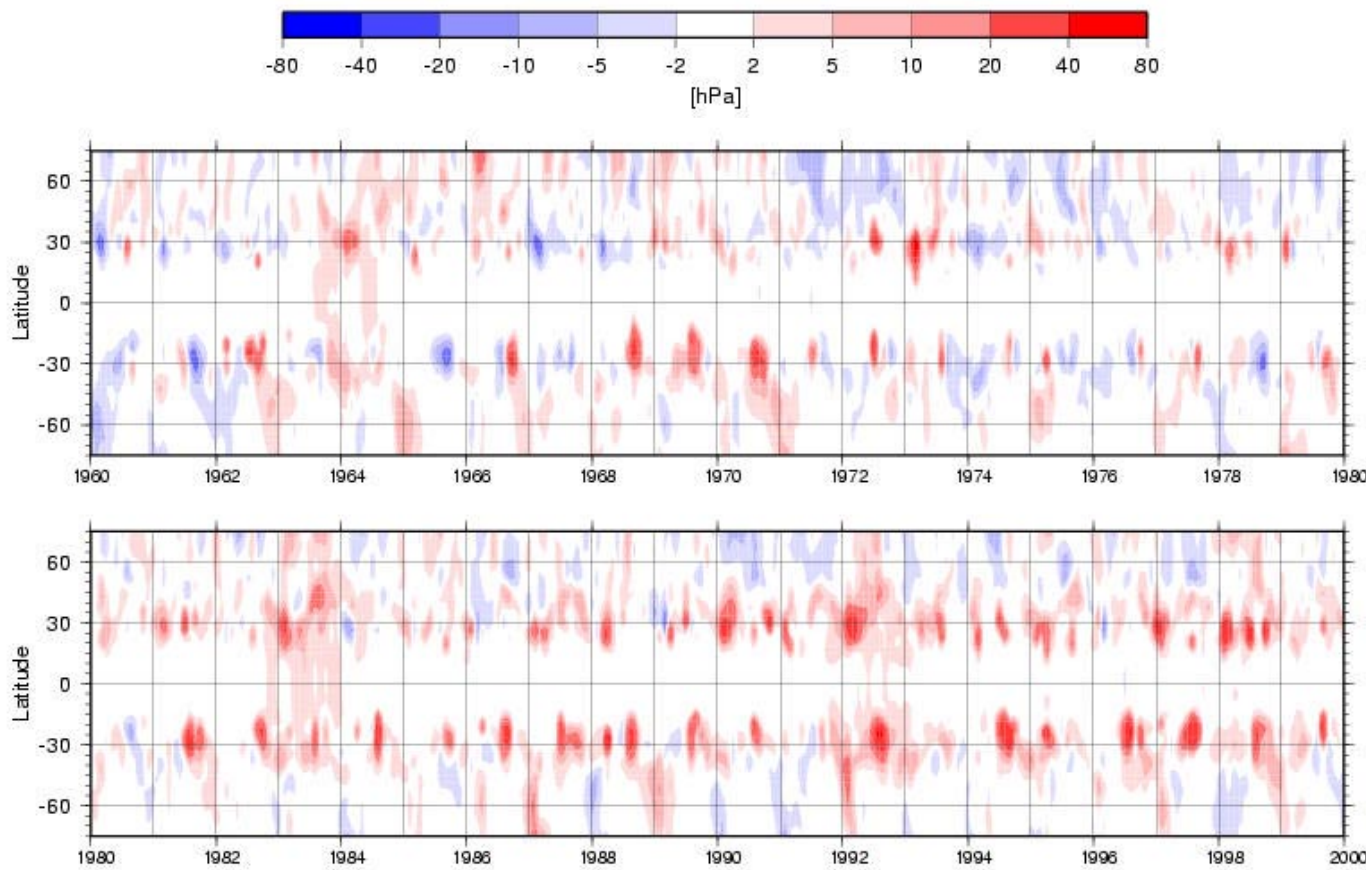

(b)

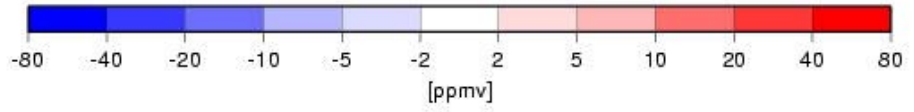

Fig. 10. Zonal mean changes of pressure (in $\mathrm{hPa}$, top panel) and of water vapour mixing ratio (in ppmv, bottom panel) at the thermal tropopause, as simulated with E39/C.

behaviour is given in Sect. 4.3. Compared with the Boulder measurements one must conclude that the water vapour signals of the large volcanic eruptions are overestimated in E39/C (see discussion in Sect. 4.1). In addition, a more de- tailed analysis of stratospheric water vapour variability and trends involving further sensitivity studies with the model system is given in Stenke and Grewe (2005). 


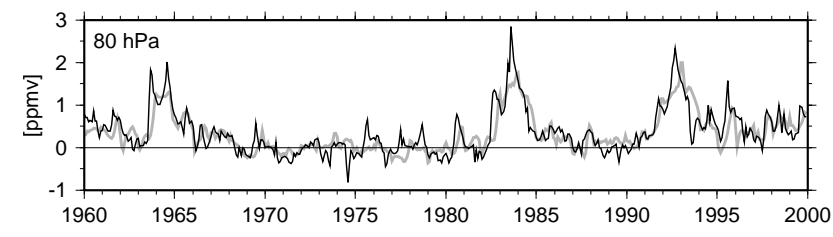

Fig. 11. Temporal development of zonal mean water vapour anomalies (in ppmv) at $40^{\circ} \mathrm{N}$ (black curve) and $40^{\circ} \mathrm{S}$ (grey curve) at $80 \mathrm{hPa}$ as simulated with E39/C. The given values of differences are with respect to reference values of the years 1960 to 1980.

\section{Variability due to external forcings}

In this section, the model response to prescribed forcings is investigated. A guiding question for the discussion is how deterministic is the response of the non-linear atmospheric (model) system? We consider both, abrupt perturbations (e.g. volcanic eruptions) and quasi-periodic forcings like the QBO and the 10 to 12 year solar activity cycle. It is important for a better understanding of the climate system to identify key parameters which are most relevant for the description of atmospheric variability and changes and which, therefore, must form the focus of quantitative assessments of future atmospheric changes. As already mentioned, we cannot expect unassailable quantitative conclusions from only one simulation. Since E39/C is driven by observed SSTs, which themselves may include a non-deterministic variability component from internal ocean fluctuations, there are obvious limitations in estimating the deterministic behaviour of the system.

\subsection{Volcanic eruptions}

Major volcanic eruptions strongly disturb the atmosphere, as many analyses of observed physical, dynamical, and chemical parameters have shown (e.g. Coffey, 1996; Angell, 1997a,b; Andronova et al., 1999; Robock, 2000). Due to upgraded observation techniques, the documentation of effects following the eruption of Mt. Pinatubo in 1991 is the most comprehensive. As described in Sect. 2, the transient simulation performed with E39/C considers the effects of volcanoes in the chemistry, as well as in the radiation scheme of the interactive model system.

Figure 12 shows a comparison of global mean temperature anomalies in the lower stratosphere derived from Microwave Sounding Unit (MSU) Channel 4 (1979-2002) and equivalent temperatures (derived according to Santer et al., 1999) from the E39/C transient simulation (1960-1999). The most obvious features are the temperature increases immediately following the eruptions of Agung, El Chichon, and Mt. Pinatubo, which reach about $2 \mathrm{~K}$ in the simulation. The main part of the model signal originates from tropical latitudes, where maxima in the zonal mean response of more than $3 \mathrm{~K}$ occur (not shown). It is evident from observations

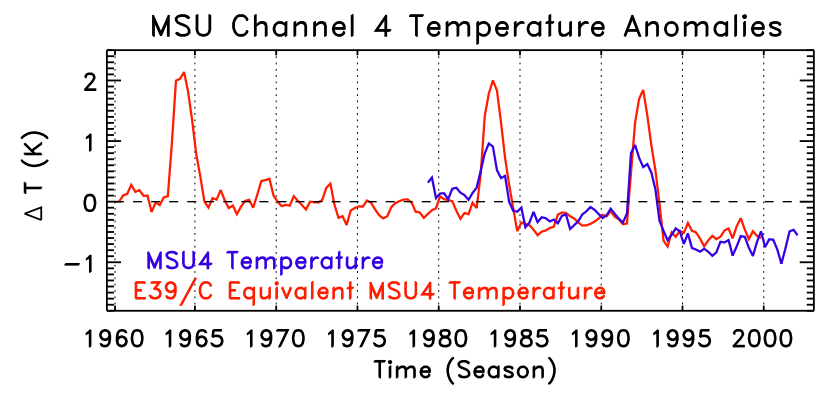

Fig. 12. Comparison of global mean temperature anomalies in the lower stratosphere (15 to $23 \mathrm{~km}$ ) derived from observations (MSU Channel 4) and equivalent values calculated from results of the E39/C model simulation.

that the model overestimates the lower stratosphere temperature response following the eruptions by about $1 \mathrm{~K}$ (see also WMO, 1986). Kirchner et al. (1999) found a 2 K excess of their simulated temperature response (near the equator at $70 \mathrm{hPa}$, see their Fig. 5b) compared to observations, which they explained by the missing QBO modulation of heating rates and missing ozone depletion in their model configuration (both effects contributing $1 \mathrm{~K}$ ). As the $\mathrm{QBO}$ has been nudged into our transient experiment (see Sects. 2.2 and 4.2), no inconsistency to observations occurs in this respect. Likewise, the $1 \mathrm{~K}$ cooling effect that observed tropical ozone depletion forces on tropical temperatures according to Kirchner et al. (1999), should be included in our simulation in case that the interactive chemistry-climate coupling produces the correct signal. A reduction of tropical ozone similar to the observed one is indeed evident in the simulation (Fig. 4, compare with Bojkov and Fioletov, 1995). We cannot convincingly explain the apparent inconsistency between the conclusions of Kirchner et al. (1999) and our results, but some possibilities are conceivable: The vertical distribution of column ozone depletion may be different in both model systems, either due to shortcomings of the chemistry-climate model or because the diagnostic method used by Kirchner et al. (1999) was too simple. Similar differences may exist with respect to the QBO induced heating rates. A further possibility is the different water vapour feedback to be expected in both simulations: As the volcano-related heating of the tropical tropopause region is higher than observed in both simulations, but more distinct in the Kirchner et al. (1999) configuration, stratospheric water vapour uptake and its related radiative cooling feedback can be expected to be stronger in the simulations of Kirchner et al. (1999). If this is correct, the aerosol absorption heating rates calculated by Kirchner et al. (1999) for the Mt. Pinatubo eruption and adopted in our simulations may overestimate the actual effect after all, as they are able to balance an exaggerated water vapour radiative cooling in the original framework, but will overdo with respect to the smaller and more realistic water vapour 
a)

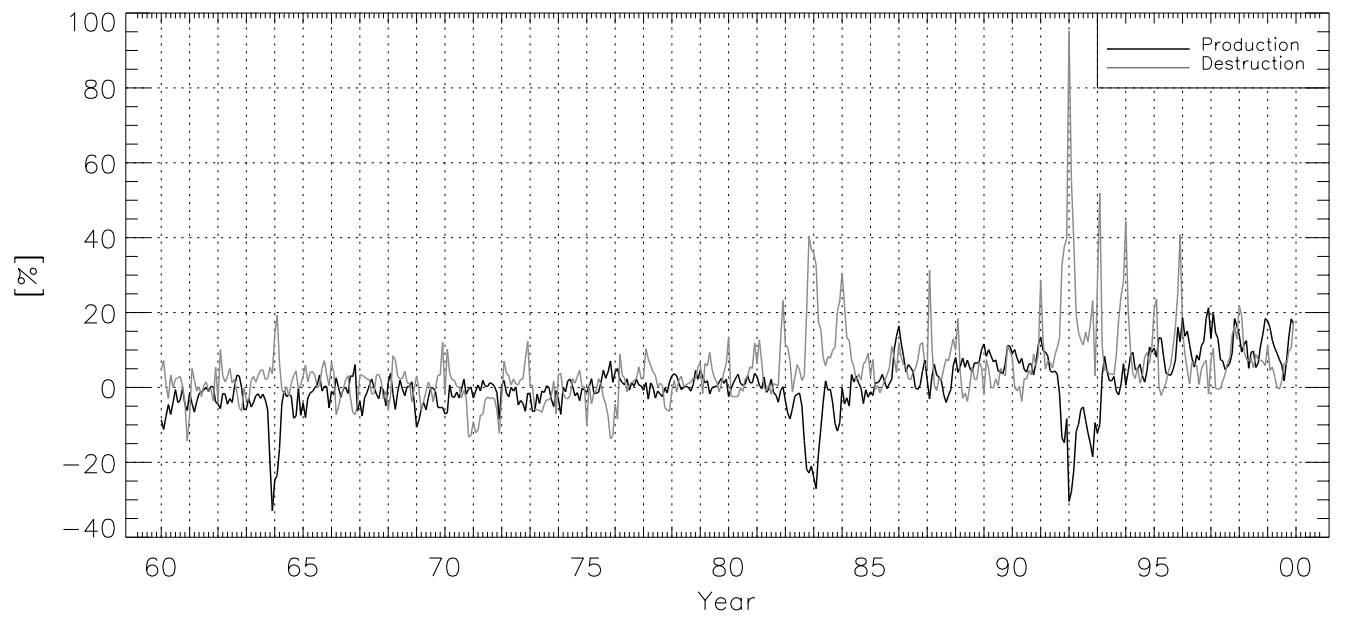

(a)

b)

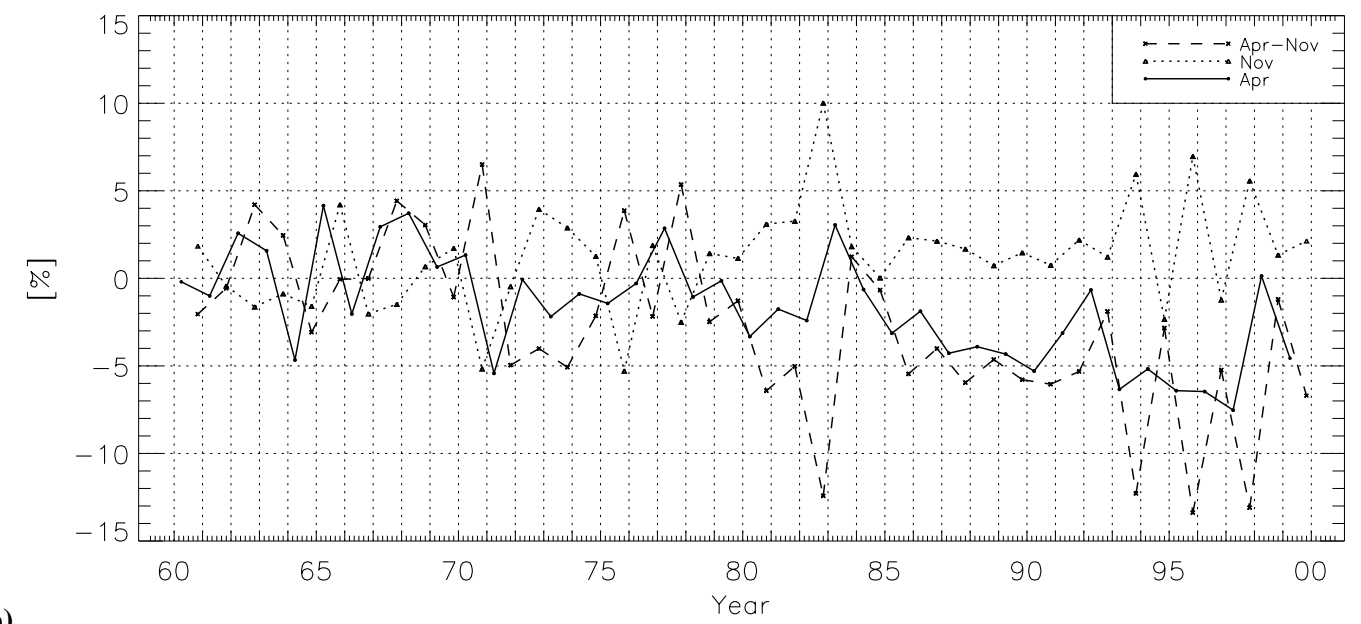

(b)

Fig. 13. Top: Monthly mean deviation of $\mathrm{O}_{3}$ production and $\mathrm{O}_{3}$ destruction at $50.1^{\circ} \mathrm{N}, 50 \mathrm{hPa}$. The deviation has been calculated separately for each month, relative to the associated reference month, as a climatological mean for 1967-1979. Bottom: Monthly mean deviation of $\mathrm{O}_{3}$ concentration for the months April, November, and the difference April-November at $50.1^{\circ} \mathrm{N}, 50 \mathrm{hPa}$. The deviation has been calculated separately for April and November, relative to the associated reference month as a climatologiocal mean for 1967-1979.

feedback in the CCM simulation. A more speculative reason for the overestimation of the volcano signal is the possible injection of moist air masses from the volcano exhaust into the stratosphere that would not be modulated by freeze drying at the tropopause. If such contribution were substantial, a mechanism of moistening and cooling the stratosphere would be absent from both the simulations of Kirchner et al. (1999) and ours.

The heating of the stratosphere caused by volcanic aerosol results not only in an increase of the stratospheric mean temperature of about $2 \mathrm{~K}$, it also enhances the meridional circulation. The vertical ascent in the tropics is amplified by roughly $20 \%$, which results in an uplift of the ozone pro- file, i.e., a vertical displacement of the ozone maximum, and a decrease of the total ozone column of approximately 5\% (Stenke and Grewe, 2005, see also Fig. 4). The water vapour in the tropical lowermost stratosphere is significantly enhanced, which leads to an increase of $\mathrm{OH}$ by 20 to $25 \%$ at $70 \mathrm{hPa}$ and a significantly stronger $\mathrm{HO}_{\mathrm{x}}$ destruction cycle. However, chemical timescales in the lower stratosphere are still long compared to the dynamical timescale so that the chemical changes have only an impact on ozone in the order of $0.1 \%$ on the total column (Stenke and Grewe, 2005).

In northern mid-latitudes $\left(40^{\circ} \mathrm{N}-50^{\circ} \mathrm{N}\right)$ at about $50 \mathrm{hPa}$ ozone concentrations are not only dynamically controlled, but also by chemistry. Relative changes of ozone production 


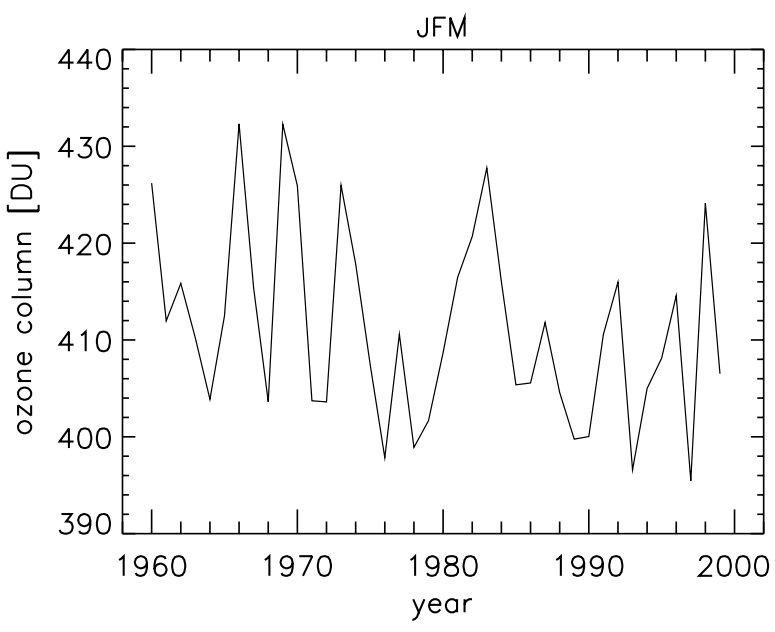

Fig. 14. Temporal development of total ozone for the midlatitude region of $30^{\circ} \mathrm{N}$ and $60^{\circ} \mathrm{N}$, calculated for January, February, and March averages, derived from E39/C model results. Values are given in DU.

and destruction cycles are similar during the three volcanic episodes, except for chlorine. Ozone production is reduced by $30 \%$ (top panel of Fig. 13), which is strongly determined by $\mathrm{NO}_{\mathrm{x}}$ removal from the gas-phase due to heterogeneous conversion (on aerosol) from $\mathrm{N}_{2} \mathrm{O}_{5}$ to $\mathrm{HNO}_{3}$. Ozone loss rates involve more complex interactions. The increase of water vapour leads to a more pronounced ozone destruction due to $\mathrm{HO}_{\mathrm{x}}$ in the order of $50 \%$ to $100 \%$. The $\mathrm{NO}_{\mathrm{x}}$ cycle is reduced by 20 to $40 \%$ due to a shift within the $\mathrm{NO}_{\mathrm{y}}$ components towards more $\mathrm{HNO}_{3}$ from the reaction $\mathrm{NO}_{2}+\mathrm{OH} \rightarrow \mathrm{HNO}_{3}$. There are other chemical reactions which have an additional influence on the $\mathrm{NO}_{\mathrm{x}}$ cycle (e.g., it should be reduced by the reaction $\mathrm{N}_{2} \mathrm{O}_{5}+\mathrm{H}_{2} \mathrm{O}$ as well), but these effects have not been analysed in detail. Ozone destruction by chlorine is doubled during the El Chichon period and even enhanced by a factor of 10 during the Pinatubo period compared to the non-volcanic period 1967 to 1979 . In total, the enhanced ozone depletion by the $\mathrm{HO}_{\mathrm{x}}$ cycle dominates during the Agung episode. During El Chichon, both the $\mathrm{HO}_{\mathrm{x}}$ and $\mathrm{ClO}_{\mathrm{x}}$ cycle are of equal importance. During the Pinatubo episode the changes in the destruction cycles are clearly dominated by the $\mathrm{ClO}_{\mathrm{x}}$ cycle. This leads to an increased ozone destruction of around $20 \%, 40 \%$, and $80 \%$ during the three volcanic episodes of Agung, El Chichon, and Mt. Pinatubo, respectively (Fig. 13a).

Using these changes in the production and loss rates, the effect on ozone is a reduction in the order of 5\% per month at $50 \mathrm{hPa}$ in the period March to May, based on a simple calculation applying the ozone production and loss terms from the climate-chemistry simulation. This leads to approximately $15 \%$ ozone loss at $50 \mathrm{hPa}$ during spring related to the Pinatubo perturbation, which can be revealed by comparing early winter (November) and late spring (April) ozone values at $50 \mathrm{hPa}$ (Fig. 13b). Both the November ozone values and the difference to the April ozone values are strongly perturbed during the post El Chichon and post Pinatubo period. Taking into account that $40 \%$ of the ozone column is affected by this process, then this reduces the ozone column by roughly $6 \%$, which agrees with observational data (WMO, 2003).

The perturbation of dynamical and chemical values and parameters discussed so far lasted only for a relatively short time period of between 1.5 and 4 years. In addition, Fig. 12 indicates that the modelled temperature trend is in good agreement with the MSU analysis. Interestingly, similar to the changes derived from MSU data, the model results also indicate stepwise changes towards lower temperatures in the lower stratosphere after the eruptions of El Chichon and Mt. Pinatubo, which is not simulated after the eruption of Agung. No temperature trend is detected in the years after El Chichon and Pinatubo, neither in MSU analysis nor in E39/C data (see also Pawson and Naujokat, 1997). Dedicated additional simulations would be necessary for a conclusive interpretation, but a plausible explanation could be the following: The eruption of Agung happened during low solar activity whereas El Chichon and Mt. Pinatubo erupted shortly after and during solar maximum, respectively. The solar cycle effect probably masks the anticipated, more or less linear negative temperature trend, which is caused by enhanced concentrations of GHGs. Slightly enhanced (reduced) temperatures are expected in the lower stratosphere during higher (lower) solar activity due to higher (lower) short-wave heating rates (e.g. Matthes et al., 2004). The calculated temperature differences (i.e. annual, global mean) between solar maximum and minimum in the lower stratosphere (around 15 to $25 \mathrm{~km}$ ) are approximately $0.2 \mathrm{~K}$ (Matthes et al., 2003), which is the same order of magnitude that is expected from the anthropogenic greenhouse effect. Therefore, in the years from 1985 to 1991 and after 1996 with increasing solar activity, the cooling of the lower stratosphere due to increasing concentrations of GHGs might be compensated such that no net temperature trend is obvious.

\subsection{The quasi-biennial oscillation}

Looking more carefully at the modelled temperature anomalies (Fig. 12), in particular in the years between 1965 and 1982, the QBO signal can be detected, which also contributes to the overall variability. A modulation of dynamical and chemical quantities caused by the prescribed QBO is also obvious in Fig. 4 in the equatorial region. Qualitatively, the QBO signal is in good agreement with a similar analysis derived from merged satellite and ground based data (Bojkov and Fioletov, 1995; updated version until the year 2000 is at our disposal, Fioletov, pers. communication). The anomalies derived from observations and the model results are of the same order of magnitude until the 1980s (i.e., up to 6\%). They are notably smaller during the 1990s in E39/C, where 
observed fluctuations have continued with similar magnitudes. Here the modelled ozone varies only by about 2 $3 \%$. It seems that in $\mathrm{E} 39 / \mathrm{C}$ the QBO signal in total ozone is partly masked by the (too) strong ozone anomalies after the volcanic eruptions. QBO signatures in E39/C can be detected in total ozone in all latitudinal regions. For example, at mid-latitudes of the Northern Hemisphere (Fig. 14), E39/C shows amplitudes in total ozone of $12 \mathrm{DU} \pm 4$ DU during winter months (JFM) which can be clearly related to the QBO. Similar results have been found in an analysis based on TOMS data (Burrows et al., 2000; see also Fig. 2.4 in ECreport, 2001). A linear regression analysis of long-term measurements of ozone at MOHp, $47.8^{\circ} \mathrm{N}$ indicates QBO-related fluctuations of $\pm 10 \mathrm{DU}$ (peak-to-trough ozone changes up to 20 DU) in February (Steinbrecht et al., 2001). The dominant effect of the QBO in the lower stratosphere is the variation of the meridional circulation and the tropical ascent. For example, in the case of a westerly phase of the QBO the meridional circulation converges horizontally towards the jet core so that the upwelling is strongly reduced (increased) in the shear layer below (above) the jet. The opposite modification is found for the meridional circulation in the vicinity of the easterly jet. The QBO signal in tropical upwelling explains enhanced water vapour and reduced $\mathrm{NO}_{\mathrm{y}}$ and ozone mixing ratios, all in the range of $5 \%$ to $10 \%$ around $50 \mathrm{hPa}$. This is consistent with the behaviour of tropospheric tracers, which are included in the model (Grewe, 2004). They do all show increased values at $50 \mathrm{hPa}$ during episodes of QBO-induced enhanced upwelling. This explains to a large extent the variations of the chemical species. Since water vapour has an opposite vertical gradient compared to $\mathrm{NO}_{\mathrm{y}}$ and ozone, the variations are anti-correlated. Variations of lower stratospheric ozone depletion in the tropics caused by the QBO are in the order of \pm 15 to $20 \%$. If chemistry leads, than increased loss rates should cause lower ozone values. This is not the case: Ozone is increased (due to transport) and then ozone loss rates are increased. Positive (negative) ozone anomalies result in enhanced (reduced) $\mathrm{NO}_{\mathrm{x}}$ and $\mathrm{HO}_{\mathrm{x}}$ destruction cycles. This gives a clear indication that the variations of the destruction cycles are a consequence of the ozone variations and not vice versa; since otherwise ozone anomalies should be correlated with the ozone loss rates. Therefore, the QBO signal in column ozone is dynamically induced with some negative feedbacks from chemistry. Returning to Fig. 12, quasi-biennial fluctuations in the global mean temperature anomalies of the lower stratosphere are visible in the E39/C data, in particular in the years between 1966 and 1982, which is a long period without major volcanic activity. After the eruptions of El Chichon and Mt. Pinatubo a similar signature cannot be identified, neither in E39/C nor in the MSU data analysis.

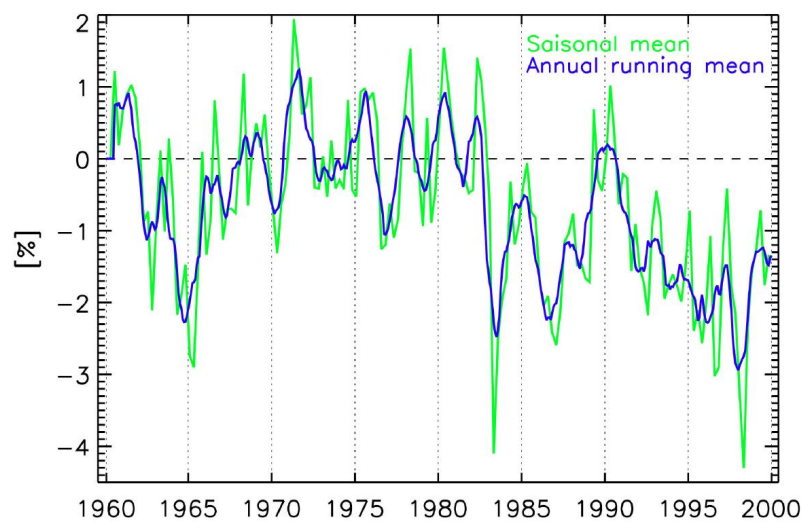

Fig. 15. Total ozone deviations (in \%) for the latitude range $25^{\circ} \mathrm{S}$ to $25^{\circ} \mathrm{N}$. Anomalies are calculated from E39/C results with respect to the model data during the years 1964 to 1980 .

\subsection{The solar cycle}

The impact of solar activity, in particular of the 11-year solar cycle, on climate and the stratosphere has often been investigated (e.g. Haigh, 1996). For example, total ozone anomalies in the tropics $\left(25^{\circ} \mathrm{N}\right.$ to $\left.25^{\circ} \mathrm{S}\right)$ have been discussed in WMO (2003; Fig. 4-5 therein), based on combined observations for the years from 1978 to 2003 (synergistic use of groundbased and satellite data). Decadal variations of total ozone in the tropics (peak-to-trough variations of about 3\%) suggest a correspondence with the activity cycle of the sun: The maxima are approximately in phase with the 11-year solar cycle.

Our transient simulation includes the effects of changing photolysis rates below $30 \mathrm{~km}$ altitude and also chemically induced ozone changes caused by prescribed time evolution of $\mathrm{NO}_{\mathrm{y}}$ at the model top. Calculated ozone anomalies in the tropical belt derived from E39/C (Fig. 15) develop similarly to observations (WMO, 2003), with positive anomalies around solar maxima (1981 and 1991) and negative anomalies around solar minima (1986 and 1996). While this is no proof for a dominating impact of solar cycle fluctuations on the tropical ozone layer, the phenomenological similarity between observed and modelled development indicates that a detailed investigation may be worthwhile. A respective paper dealing with the separation of the solar signal in dynamic and chemical components is in preparation. Interestingly, before 1978 the solar signal is less but still suggested by higher ozone values around 1960 and 1969 in comparison to 1965 . Note that the solar cycle between 1965 and 1976 was less distinct, according to $10.7 \mathrm{~cm}$ radiation intensity records, than the other cycles included in the period. Recalling discussions in previous sections a distinct QBO signal is immediately evident in Fig. 15.

To get a better insight into the radiative impact of solar activity changes on dynamics and chemistry in E39/C, it is helpful to have a look at the long-term variability of ozone 
Production: $\mathrm{O}_{2}+\mathrm{h} \nu\left(+2 \mathrm{O}_{2}\right)->2 \mathrm{O}_{3}$

$10 \mathrm{hPa}$

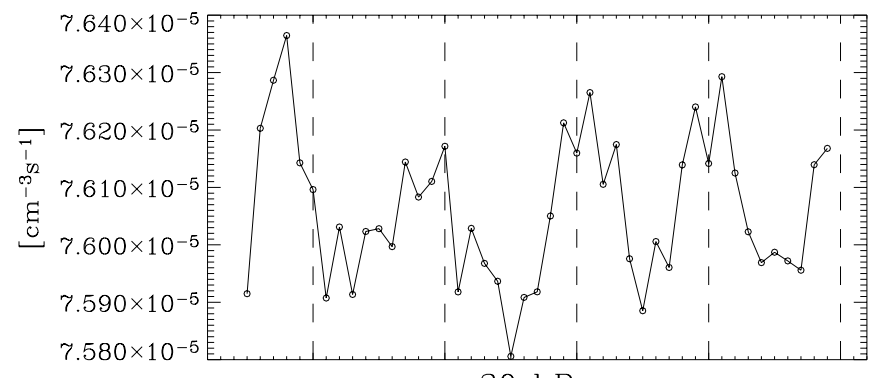

$30 \mathrm{hPa}$
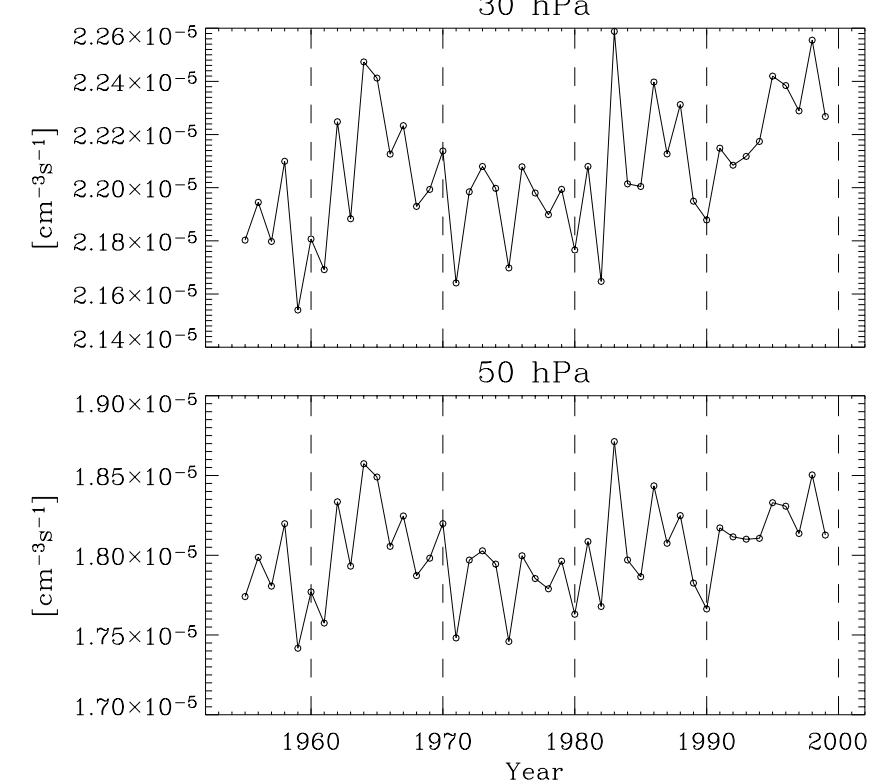

Photolysis rate: $\mathrm{O}_{3}->\mathrm{O}\left({ }^{1} \mathrm{D}\right)$

$10 \mathrm{hPa}$

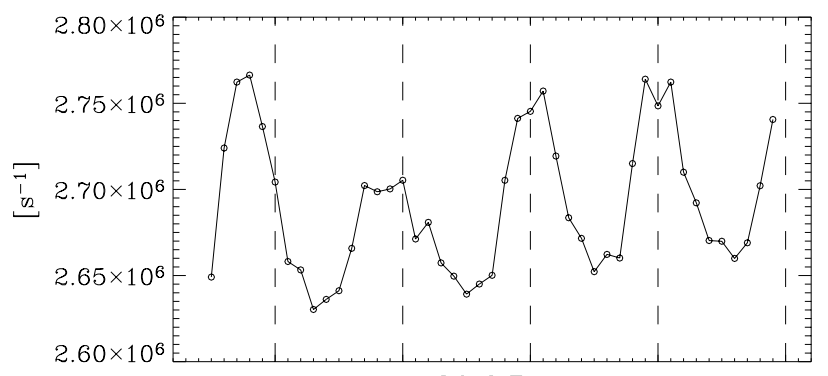

$30 \mathrm{hPa}$

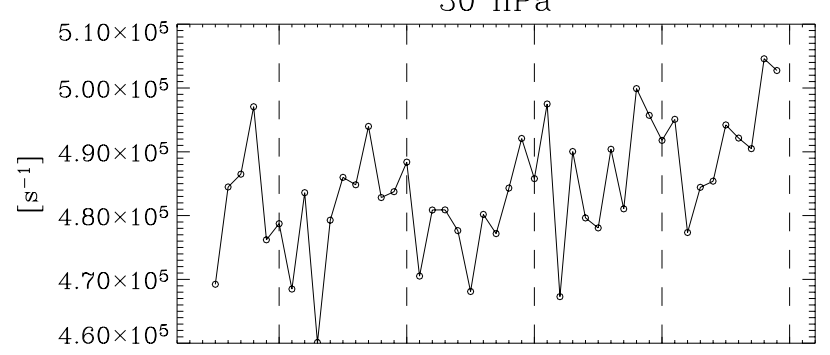

$50 \mathrm{hPa}$

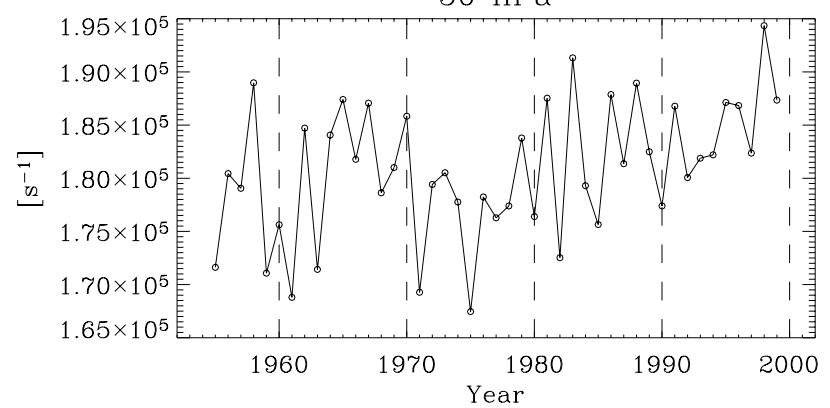

Fig. 16. Temporal development of ozone production rates (left, in $\mathrm{cm}^{-3} \mathrm{~s}^{-1}$ ) and ozone photolysis rates (right, in $\mathrm{s}^{-1}$ ) at $10 \mathrm{hPa}$ (top), $30 \mathrm{hPa}$ (middle), and $50 \mathrm{hPa}$ (bottom), for the latitude range $25^{\circ} \mathrm{S}$ to $25^{\circ} \mathrm{N}$.

photolysis and production rates during the 40 year transient simulation. Figure 16 shows respective results of E39/C at 10,30 , and $50 \mathrm{hPa}$ at lower latitudes $\left(25^{\circ} \mathrm{N}\right.$ to $\left.25^{\circ} \mathrm{S}\right)$. The values calculated at $10 \mathrm{hPa}$ directly reflect the prescribed changes of the extra-terrestrial flux at the upper boundary of E39/C. This must be kept in mind because the low upper boundary conditionally implies some uncertainties on causes and effects in this case. For example, the largest percentage ozone changes have been found in the upper stratosphere (e.g. Haigh, 1996). While this does not significantly change the total ozone column, it might have a dynamical influence on the lower and middle stratosphere. In the model, the solar signal can, to some part, still be identified at $30 \mathrm{hPa}$, the picture changes further down in the lower stratosphere. At $50 \mathrm{hPa}$, the 11-year solar cycle is no longer obvious because of feedback processes (e.g., interactive ozone) and the influence of volcanic eruptions. Here, changes of ozone photolysis and production on longer time scales are identified, with minimum ozone photolysis and production rates in 1975 and higher values before and after that year. Interestingly, corresponding similar long-term changes are found in other model data sets: For example, in Sect. 3.3 it is shown that water vapour mixing ratios at mid-latitudes of the lower stratosphere slightly increase in the 1980s and 1990s, which is supported by observations at the Boulder station (Oltmans et al., 2000). Model results for the 1970s indicate lowest water vapour mixing ratios without a visible trend and decreasing mixing ratios in the 1960s, whereas the values in the early 1960s are similar to those of the late 1990s. We explain these changes of water vapour mixing ratios with a corresponding behaviour of the cold-point temperature (not shown), which modifies the transport of water vapour from the troposphere into the stratosphere: A decrease of the coldpoint temperature is found from 1960 until the early 1970s (i.e. around $1 \mathrm{~K}$ ) and an increase of approximately $0.5 \mathrm{~K}$ is calculated from the beginning 1980s to 1999. Based on the currently available model results we speculate, although we cannot definitely conclude on the basis of this analysis, 
that long-term changes of the cold-point temperature are a consequence of solar activity fluctuations (i.e., via changes in photolysis rates, ozone production and concentration, net heating rates).

An additional parameter which is reportedly influenced by long-term changes of solar activity is the duration of the stratospheric summer circulation at northern mid- and high latitudes (Offermann et al., 2004). They showed on the basis of meteorological analyses (e.g. NCEP, Berlin data) that the duration of summer (i.e., number of days with zonal mean east winds in $50^{\circ}$ to $80^{\circ} \mathrm{N}$ and $60^{\circ}$ to $80^{\circ} \mathrm{S}$ at 10 and $30 \mathrm{hPa}$ ) decreases in the 1980s and 1990s by about 10 to 20 days (depending on latitude and altitude), whereas the length of summer increases in the 1960s and 1970s by the same order of magnitude. It seems plausible that the changes found in the 1980s and 1990s may have something to do with the anthropogenic greenhouse effect and the depletion of stratospheric ozone, which both lead to a more persistent polar vortex in winter. But this explanation does not hold for the description of changes found in the 1960s and 1970s. An analysis of summer duration in the E39/C transient simulation indicates a qualitatively similar behaviour as described in Offermann et al. (2004). On the basis of this result, we conclude that although solar activity is not the major driver of long-term changes of dynamical and chemical values and parameters in the lower stratosphere, it might have a stronger impact on stratospheric composition and circulation than previously expected.

We are aware that the evidence of solar variability effects in the transient simulation cannot be demonstrated convincingly by the few parameters reviewed here. Probably, as experience with conventional climate models without chemistry shows (e.g. Stott et al., 2002), an ensemble of transient simulations will be necessary to establish significant signals. This certainly holds for studies dealing with the proposed interaction between solar cycle and QBO to modify the northern hemisphere stratospheric circulation (Labitzke and van Loon, 1988). However, results presented here indicate that signals in chemical parameters (like water vapour and ozone) are likely to exist. Hence it appears worthwhile to extend our coupled CCM studies with simulations using offline chemistry (e.g. Matthes et al., 2003) to clarify the role of chemical feedbacks for dynamical changes.

\subsection{Summary and discussion}

It is noteworthy to which extent the temporal and spatial development of atmospheric parameters in the transient E39/C CCM simulation matches with several observed features. On the one hand it is not surprising that the model is able to reasonably reproduce mean conditions and seasonal, interannual and long-term variability, since former investigations based upon E39/C time-slice experiments (e.g. Hein et al., 2001; Schnadt et al., 2002; Austin et al., 2003) already indicate the capabilities of the coupled model system. On the other hand, it is not self-evident that a number of transient features and trends agree well in space and time with observations, especially as we have only one realisation of the 40-year time series available and, thus, could not reduce the stochastic component of the dynamics by ensemble averaging. The most remarkable examples are identified in the temporal development of ozone anomalies (Fig. 4): Consecutive cold and stable Northern Hemisphere winters in the stratosphere during the first half of the 1990s connected with low ozone columns; weak ozone hole events in 1986 and 1988; Southern Hemisphere mid-latitude anomalies in the years 1985, 1989, 1991/1992, and 1996. A possible explanation is that the prescribed SST, containing specific anomaly events (e.g., El Niño, La Niña), is a major driver for changes in planetary wave activity, which has a strong influence on the dynamics of the stratosphere, e.g., the Brewer-Dobson circulation. Additionally, the QBO filters waves propagating to the tropical stratosphere and modulates wave dynamics in the stratospheric wave guide. The reproduction of the positive water vapour trend in the lower stratosphere during the 1980s and 1990s is very encouraging for a more detailed study of the underlying cause and effect relationship. Changes in solar radiation due to the 11-year solar activity cycle is, evidently, another source for variations in the dynamical and chemical state of the simulated atmosphere, calling for specific sensitivity experiments.

The importance of the QBO and solar activity cycle for stratospheric dynamics has been discussed for many years (e.g. Holton and Tan, 1980; Dameris and Ebel, 1990; Holton and Austin, 1991; Labitzke and van Loon, 2000). It is generally agreed that both influence to a large part the dynamical behaviour of the stratosphere, and therefore also the transport of tracers which impacts the chemical composition. The examples of E39/C results presented in this paper confirm that it is necessary to consider all major forcing mechanisms to obtain a realistic variability of dynamical and chemical values and parameters. The picture is not as suggestive for the role of the SST. Schnadt and Dameris (2003) showed that $\mathrm{E} 39 / \mathrm{C}$ is able to reproduce the observed correlation of the North Atlantic Oscillation (NAO) pattern and the Northern Hemisphere polar winter vortex: In the positive NAO phase the stratospheric vortex is stronger and colder than in the negative NAO phase. In the troposphere, the positive NAO phase is associated with an enhanced variance across the North Atlantic storm track whereas the negative NAO phase is suggestive of blocking. It was demonstrated that the vertical propagation of stationary (transient) planetary waves is reduced (enhanced) during the positive NAO phase, which clearly shows the link between SST and stratospheric dynamics. Multi-annual sensitivity simulations of 20 years each with the Met Office Unified Model have been investigated by Braesicke and Pyle (2004). For their experiments they changed the prescribed SSTs. They found that the appearance of extreme events in the Northern Hemisphere winter stratosphere is rather linked to the representation of SSTs 
than it is to ozone. The significance of interannual variability in SSTs on stratospheric dynamics and ozone was demonstrated. Therefore, the underlying SST is at least partly responsible for tropospheric circulation changes, certainly modifying the generation and propagation of planetary waves, which have an important influence on stratospheric dynamics.

\section{Outlook}

The results discussed in this paper indicate where differences between model and observations are still obvious and where a detailed investigation of realistically simulated variability and trend components appear promising in order to improve the understanding of underlying processes and feedbacks. Such complementary investigations will be discussed in further papers, as they require a more dedicated and detailed analysis of correlations and interactions, also including parameters for which long-term observations lack. Additional sensitivity experiments with the same model system may also be required for such studies but considering the computational demands of CCMs those cannot be provided in this study.

Acknowledgements. We especially thank V. Fioletov for providing an update of total ozone anomaly analysis for comparison with the model data, and I. Kirchner for providing heating rates calculated for the post-Pinatubo period. The authors wish to thank the German government (BMBF) and the European Commission for funding the projects KODYACS (within the German Atmosphere Research Programme AFO2000), TOPOZ-III and SCENIC (both within the 5th framework programme), and SCOUT-O3 (within the 6th framework programme).

Edited by: P. Haynes

\section{References}

Andronova, N. G., Rozanov, E. V., Yang, F., Schlesinger, M. E., and Stenchikov, G. L.: Radiative forcing by volcanic aerosols from 1850 to 1994, J. Geophys. Res., 104, 16 807-16 826, 1999.

Angell, J. K.: Estimated impact of Agung, El Chichon, and Pinatubo volcanic eruptions on global and regional total ozone after adjustment for the QBO, Geophys. Res. Lett., 24, 647-650, 1997a.

Angell, J. K.: Stratospheric warming due to Agung, El Chichon, and Pinatubo taking into account the quasi-biennial oscillation, J. Geophys. Res., 102, 9479-9485, 1997 b.

Austin, J.: A three-dimensional coupled chemistry-climate model simulation of past stratospheric trends, J. Atmos. Sci., 59, 218232, 2002.

Austin, J., Shindell, D., Beagley, S. R., Brühl, C., Dameris, M., Manzini, E., Nagashima, T., Newman, P., Pawson, S., Pitari, G., Rozanov, E., Schnadt, C., and Shepherd, T. G.: Uncertainties and assessments of chemistry-climate models of the stratosphere, Atmos. Chem. Phys., 3, 1-27, 2003,

SRef-ID: 1680-7324/acp/2003-3-1.
Benkovitz, C. M., Scholtz, M. T., Pacyna, J., Tarrason, L., Dignon, J., Voldner, E. C., Spiro, P. A., Logan, J. A., and Graedel, T. E.: Global gridded inventories of anthropogenic emissions of sulfur and nitrogen, J. Geophys. Res., 101, 29239-29 253, 1996.

Bojkov, R. D. and Fioletov, V. E.: Estimating the global ozone characteristics during the last 30 years, J. Geophys. Res., 100, 16 537-16 551, 1995.

Braesicke, P. and Pyle, J. A.: Sensitivity of dynamics and ozone to different representations of SSTs in the Unified Model, Q. J. R. Meteorol. Soc., 99, 1-9, 2004.

Brühl, C. and Crutzen, P. J.: MPIC two-dimensional model, NASA Ref. Publ. 1292, 103-104, 1993.

Burrows, J. P., Gleason, J., Labow, G., Eichmann, K.-U., Bramstedt, K., and Weber, M.: An overview of the stratosphere 1995-1999 as measured by GOME, Stratospheric Ozone 1999, in: Proceedings of the fifth European symposium, edited by: Harris, N. R. P., Guirlet, M., Amanatidis, G. T., 27 September-1 October 1999, Saint Jean de Luz, France, Air Pollution Reseach Report No. 73, EUR 19340, ISBN 92-827-5672-6, 2000.

Chubachi, S.: A special ozone observation at Syowa Station, Antarctica from February 1982 to January 1983, in: Atmospheric Ozone: Proceedings of the Quadrennial Ozone Symposium, edited by: Zerefos, C. S. and Ghazi, A. M., Halkidiki, Greece, 3-7 September 1984, 285-289, 1985.

Coffey, M. T.: Observations of the impact of volcanic activity on stratospheric chemistry, J. Geophys. Res., 101, 6767-6780, 1996.

Corbett, J. J., Fischbeck, P. S., and Pandis, S. N.: Global nitrogen and sulphur inventories for ocean-going ships, J. Geophys. Res., 104, 3457-3470, 1999.

Dameris, M. and Ebel, A.: The quasi-biennial oscillation and major stratospheric warmings: A three-dimensional model study, Ann. Geophys., 8, 79-86, 1990.

EC-report: European research in the stratosphere 1996-2000, Advances in our understanding of the ozone layer during THESEO, EUR 19 867, ISBN 92-894-1398-0, 378pp., 2001.

Eyring, V., Köhler, H. W., van Aardenne, J., and Lauer, A.: Emissions from international shipping. Part 1: The last 50 years, J. Geophys. Res., in press, 2005a.

Eyring V., Harris, N. R. P. , Rex, M., Shepherd, T. G., Fahey, D. W., Amanatidis, G. T., Austin, J., Chipperfield, M. P., Dameris, M., De F. Forster, P. M., Gettelman, A., Graf, H.-F., Nagashima, T., Newman, P. A., Pawson, S., Prather, M. J., Pyle, J. A., Salawitch, R. J., Santer, B. D., and Waugh, D. W.: A strategy for process-oriented validation of coupled chemistry-climate models, Bull. Am. Meteorol. Soc., in press, 2005b.

Farman, J. C., Gardiner, B. G., and Shanklin, J. D.: Large losses of total ozone in Antarctica reveal seasonal $\mathrm{ClO}_{\mathrm{x}} / \mathrm{NO}_{\mathrm{x}}$ interaction, Nature, 315, 207-210, 1985.

Forster, P. M. de F. and Shine, K. P.: Assessing the climate impact of trends in stratospheric water vapor, Geophys. Res. Lett., 29, 1086, doi:10.1029/2001GL013909, 2002.

Fortuin, J. P. F. and Kelder, H.: An ozone climatology based on ozonesonde and satellite measurements, J. Geophys. Res., 103, 31 709-31 734, 1998.

Fouquart, Y. and Bonnel, B.: Computation of solar heating of the Earth's atmosphere: A new parameterization, Beitr. Phys. Atmosph., 53, 35-62, 1980. 
Giorgetta, M. and Bengtsson, L.: Potential role of the quasi-biennial oscillation in the stratosphere-troposphere exchange as found in water vapor in general circulation model experiments, J. Geophys. Res., 104, 6003-6020, 1999.

Grewe, V., Dameris, M., Hein, R., Sausen, R., Steil, B.: Future changes of the atmospheric composition and the impact of climate change, Tellus, 53B, 103-121, 2001a.

Grewe, V., Brunner, D., Dameris, M., Grenfell, J. L., Hein, R., Shindell, D., and Staehelin, J.: Origin and variability of upper tropospheric nitrogen oxides and ozone at northern mid-latitudes, Atmos. Environ., 35, 3421-3433, 2001 b.

Grewe, V.: Technical Note: A diagnostic for ozone contributions of various $\mathrm{NO}_{\mathrm{x}}$ emissions in multi-decadal chemistry-climate model simulations, Atmos. Chem. Phys., 4, 729-736, 2004,

SRef-ID: 1680-7324/acp/2004-4-729.

Haigh, J.: The impact of solar variability on climate, Science, 272, 981-984, 1996

Hao, W. M., Liu, M.-H., and Crutzen, P. J.: Estimates of annual and regional releases of $\mathrm{CO}_{2}$ and other trace gases to the atmosphere from fires in the tropics, based on the FAO statistics for the period 1975-1980, in: Fire in the Tropical Biota, Ecological Studies 84, edited by: Goldammer, J. G., Springer-Verlag, New York, USA, 440-462, 1990.

Hein, R., Crutzen, P. J., and Heimann, M.: An inverse modeling approach to investigate the global atmospheric methane cycle, Global Biogeochem. Cycles, 11, 43-76, 1997.

Hein, R., Dameris, M., Schnadt, C., Land, C., Grewe, V., Köhler, I., Ponater, M., Sausen, R., Steil, B., Landgraf, J., Brühl, C.: Results of an interactively coupled atmospheric chemistry-general circulation model: Comparison with observations, Ann. Geophys., 19, 435-457, 2001,

\section{SRef-ID: 1432-0576/ag/2001-19-435.}

Holton, J. R. and Tan, H.-C.: The influence of the equatorial quasibiennial oscillation on the global circulation at $50 \mathrm{mb}$, J. Atmos. Sci., 37, 2200-2208, 1980.

Holton, J. R. and Austin, J.: The influence of the equatorial QBO on sudden stratospheric warmings, J. Atmos. Sci., 48, 607-618, 1991.

IPCC (Intergovernmental Panel on Climate Change): Special report on aviation and the global atmosphere, edited by: Penner, J. E., Lister, D. H., Griggs, D. J., Dokken, D. J., McFarland, M., Cambridge University Press, Cambridge, United Kingdom and New York, NY, USA, 373pp., 1999.

IPCC (Intergovernmental Panel on Climate Change): Climate change 2001: The scientific basis. Contribution of Working Group 1 to the Third Assessment Report, edited by: Houghton, J. T., Cambridge University Press, Cambridge, United Kingdom and New York, NY, USA, 881pp., 2001.

Jackman, C. H., Fleming, E. L., Chandra, S., Considine, D. B., Rosenfield, J. E.: Past, present, and future modeled ozone trends with comparisons to observed trends, J. Geophys. Res., 101, 28753-28767, 1996.

Johnson, C. E., Collins, W. J., Stevenson, D. S., and Derwent, R. G.: The relative roles of climate and emission changes on future tropospheric oxidant concentrations, J. Geophys. Res., 104, 18 631-18 645, 1999.

Joshi, M. M. and Shine, K. P.: A GCM study of volcanic eruptions as a cause of increased stratospheric water vapor, J. Clim., 16, 3525-3534, 2003.
JPL (Jet Propulsion Laboratory): Chemical kinetics and photochemical data for use in stratospheric modeling: Evaluation 13. JPL-00-3, NASA Panel for Data Evaluation, NASA Aeronautics and Space Administration, Pasadena, CA, USA, 73pp., 2000.

Junge, C., Chagnon, C., Manson, J.: Stratospheric aerosols, J. Meteorol., 18, 81-108, 1961.

Kirchner, I., Stenchikov, G. L., Graf, H.-F., Robock, A., and Antuna, J. C.: Climate model simulation of winter warming and summer cooling following the 1991 Mount Pinatubo volcanic eruption, J. Geophys. Res., 104, 19 039-19 055, 1999.

Kurz, C. and Grewe, V.: Lightning and thunderstorms, Part I: observational data and model results, Meteorol. Z., 11, 379-393, 2002.

Labitzke, K.: Stratospheric temperature changes after the Pinatubo eruption, J. Atmos. Terr. Phys., 56, 1027-1034, 1994.

Labitzke, K. and van Loon, H.: Associations between the 11-year solar cycle, the QBO and the atmosphere, part I: The troposphere and stratosphere in the Northern Hemisphere in winter, J. Atmos. Terr. Phys., 50, 197-206, 1988.

Labitzke, K. and Naujokat, B.: The lower arctic stratosphere in winter since 1952, SPARC Newsletter, 15, 11-14, 2000.

Labitzke, K. and van Loon, H.: The QBO effect on the solar signal in the global stratosphere in the winter of the Northern Hemisphere, J. Atmos. Terr. Phys., 62, 621-628, 2000.

Labitzke, K., et al.: The Berlin stratospheric data set, CD from Meteorological Institute, Free University Berlin, 2002.

Lamago, D., Dameris, M., Schnadt, C., Eyring, V., and Brühl, C.: Impact of large solar zenith angles on lower stratospheric dynamical and chemical processes in a coupled chemistry-climate model, Atmos. Chem. Phys., 3, 1981-1990, 2003, SRef-ID: 1680-7324/acp/2003-3-1981.

Land, C., Feichter, J., and Sausen, R.: Impact of vertical resolution on the transport of passive tracers in the ECHAM4 model, Tellus, 54B, 344-360, 2002.

Landgraf, J. and Crutzen, P. J.: An efficient method for online calculations of photolysis and heating rates, J. Atmos. Sci., 55, 863 878, 1998.

Lean, J., Rottmann, G., Kyle, H., Woods, T., Hickey, J., and Puga, L.: Detection and parameterisation of variations in solar midand near-ultraviolet radiation (200-400 nm), J. Geophys. Res., 102, 29 939-29 956, 1997.

Manzini, E., Steil, B., Brühl, C., Giorgetta, M. A., and Krüger, K. A new interactive chemistry climate model: 2 . Sensitivity of the middle atmosphere to ozone depletion and increase in greenhouse gases and implications for recent stratospheric cooling, J. Geophys. Res., 108, 4429, doi:10.1029/2002JD002977, 2003.

Matthes, K., Kodera, K., Haigh, J. D., Shindell, D. T., Shibata, K., Langematz, U., Rozanov, E., and Kuroda, Y.: GRIPS solar experiments intercomparison project: Initial results, Pap. Meteorol. Geophys., 54, 71-90, 2003.

Matthes, K., Langematz, U., Gray, L. L., Kodera, K., and Labitzke, K.: Improved 11-year solar signal in the Freie University Berlin climate middle atmosphere model, J. Geophys. Res., 109, D06101, doi:10.1029/2003JD004012, 2004.

Matthes, S.: Globale Auswirkungen des Straßenverkehrs auf die chemische Zusammensetzung der Atmosphäre, $\mathrm{PhD}$ thesis, Ludwig-Maximilians Universität München, DLR-Report 200315, ISSN 1434-8454, 160pp., 2003. 
Mc Cormick, M. P., Thomason, L. W., and Trepte, C. R.: Atmospheric effects of the Mt. Pinatubo eruption, Nature, 373, 399404, 1995.

Mc Peters, R. D., Hollandsworth, S. M., Flynn, L. E., Herman, J. R., and Seftor, C. J.: Long-term ozone trends derived from the 16-year combined Nimbus 7/Meteor 3 TOMS version 7 record, Geophys. Res. Lett., 23, 3699-3702, 1996.

Morcrette, J. J.: Radiation and cloud radiative properties in the European Centre for Medium Range Weather Forecasts forecasting system, J. Geophys. Res., 96, 9121-9132, 1991.

Nagashima, T., Takahashi, M., Takigawa, M., and Akiyoshi, H.: Future development of the ozone layer calculated by a general circulation model with fully interactive chemistry, Geophys. Res. Lett., 29, 1162, doi:10.1029/2001GL014026, 2002.

Naujokat, B.: An update of the observed quasi-biennial oscillation of the stratospheric winds over the tropics, J. Atmos. Sci., 43, 1873-1877, 1986.

Naujokat B. and Pawson, S.: The cold stratospheric winters 1994/1995 and 1995/1996, Geophys. Res. Lett., 23, 3703-3706, 1996.

Naujokat, B., Pawson, S., and Piel, A.: Is there a trend in the occurrence of extremely low temperatures in the northern stratospheric winters? Proceedings of the first SPARC General Assembly, Melbourne, Australia, 2-6 December 1996, WCRP-99, WMO/TD-NO. 814, 157-160, 1997.

Offermann, D., Donner, M., Knieling, P., Naujokat, B.: Middle atmosphere temperature changes and the duration of summer, J. Atmos. Sol. Terr. Phys., 66, 437-450, 2004.

Oltmans, S. J., Vömel, H., Hofmann, D. J., Rosenlof, K. H., and Kley, D.: The increase in stratospheric water vapor from balloonborne, frostpoint hygrometer measurements at Washington D.C., and Boulder, Colorado, Geophys. Res. Lett., 27, 3453 3456, 2000.

Parker, D. E., Gordon, M., Cullum, D. P. N., Sexton, D. M. H., Folland, C. K., and Rayner, N.: A new global gridded radiosonde temperature data base and recent temperature trends, Geophys. Res. Lett., 24, 1499-1502, 1997.

Pawson, S. and Naujokat, B.: Trends in daily wintertime temperatures in the northern stratosphere, Geophys. Res. Lett., 24, 575578, 1997.

Pawson, S. and Naujokat, B.: The cold winters of the middle 1990s in the northern lower stratosphere, J. Geophys. Res., 104, 14 209-14 222, 1999.

Pawson, S., Kodera, K., Hamilton, K., et al.: The GCM-reality intercomparison project for SPARC (GRIPS): Scientific issues and initial results, Bull. Amer. Met. Soc., 81, 781-796, 2000.

Pickering, K., Wang, Y., Tao, W.-K., Price, C., Muller, F.-J.: Vertical distribution of lightning $\mathrm{NO}_{\mathrm{x}}$ for use in regional and global chemical transport models, J. Geophys. Res., 103, 31203 31216,1998

Pitari, G., Manzini, E., Rizi, V., and Shindell, D.: Impact of future climate and emission changes on stratospheric aerosols and ozone, J. Atmos. Sci., 59, 414-440, 2002.

Price, C. and Rind, D.: A simple lightning parameterization for calculating global lightning distributions, J. Geophys. Res., 97, 9919-9933, 1992.

Price, C. and Rind, D.: What determines the cloud-to-ground fraction of lightning in thunderstorms?, Geophys. Res. Lett., 20, 463-466, 1993
Randel, W. J. and Wu, F.: Cooling of the Arctic and Antarctic polar stratospheres due to ozone depletion, J. Climate, 12, 1467-1479, 1999.

Randel, W. J., Wu, F., Oltmans, S. J., Rosenlof, K., and Nedoluha, G. E.: Interannual changes of stratospheric water vapor and correlations with tropical tropopause temperatures, J. Atmos. Sci., 61, 2133-2147, 2004.

Rayner, N. A., Parker, D. E., Horton, E. B., Folland, C. K., Alexander, L. V., Rowell, D. P., Kent, E. C., and Kaplan, A.: Global analyses of sea surface temperatures, sea ice, and night marine air temperature since the late nineteenth century, J. Geophys. Res., 108, 4407, doi:10.1029/2002JD002670, 2003.

Rex, M., Salawitch, R. J., von der Gathen, P., Harris, N. R. P., Chipperfield, M. P., and Naujokat, B.: Arctic ozone loss and climate change, Geophys. Res. Lett., 31, L04116, doi:10.1029/2003GL018844, 2004.

Robock, A.: Volcanic eruptions and climate, Rev. Geophys., 38, 191-219, 2000.

Rosenfield, J., Considine, D., Meade, P., Bacmeister, J., Jackman, C., and Schoeberl, M.: Stratospheric effects of Mount Pinatubo aerosol studied with a coupled two-dimensional model, J. Geophys. Res., 102, 3649-3670, 1997.

Rosenlof, K. H., Oltmans, S. J., Kley, D., Russell III, J. M., Chiou, E.-W., Chu, W. P., Johnson, D. G., Kelly, K. K., Michelsen, H. A., Nedoluha, G. E., Remsberg, E. E., Toon, G. C., and McCormick, M. P.: Stratospheric water vapor increases over the past half-century, Geophys. Res. Lett., 28, 1195-1198, 2001.

Rosenlof, K. H.: Transport changes inferred from HALOE water and methane measurements, J. Meteorol. Soc. Japan, 80, 831848, 2002.

Rozanov, E. V., Schlesinger, M. E., and Zubov, V. A.: The University of Illinois at Urbana-Champaign three-dimensional stratosphere-troposphere general circulation model with interactive ozone photochemistry: Fifteen-year control run climatology, J. Geophys. Res., 106, 27 233-27 254, 2001.

Santer, B. D., Hnilo, J. J., Wigley, T. G., Boyle, J. S., Doutriaux, C., Fiorino, M., Parker, D. E., and Taylor, K. E.: Uncertainties in observationally based estimates of temperature change in the free atmosphere, J. Geophys. Res., 104, 6305-6333, 1999.

Santer, B. D., Wehner, M. F., Wigley, T. G., Sausen, R., Meehl, G. A., Taylor, K. E., Ammann, C., Arblaster, J., Washington W. M., Boyle, J. S., and Brüggemann, W.: Contributions of anthropogenic and natural forcing to recent tropopause height changes, Science, 301, 479-483, 2003.

Sato, M., Hansen, J. E., McCormick, M. P., Pollack, J. B.: Stratospheric aerosol optical depths, 1850-1990, J. Geophys. Res., 98 22 987-22 994, 1993

Schmitt, A., and Brunner, B.: Emissions from aviation and their development over time, in: Pollutants from air traffic - results of atmospheric research 1992-1997, DLR-Mitt. 97-04, edited by: Schumann, U., Chlond, A., Ebel, A., Kärcher, B., Pate, H., Schlager, H., Schmitt, A., and Wendling, P., 37-52, DLR Köln, Germany, 1997.

Schnadt, C., Dameris, M., Ponater, M., Hein, R., Grewe, V., and Steil, B.: Interaction of atmospheric chemistry and climate and its impact on stratospheric ozone, Clim. Dyn., 18, 501-517, 2002.

Schnadt, C. and Dameris, M.: Relationship between North Atlantic Oscillation changes and stratospheric ozone recovery in 
the northern hemisphere in a chemistry-climate model, Geophys. Res. Lett., 30, 1487, doi:10.1029/2003GL017006, 2003.

Shindell, D. J., Grenfell, J. L., Rind, D., Grewe, V., Price, C.: Chemistry-climate interactions in the Goddard Institute for Space Studies general circulation model. 1. Tropospheric chemistry model description and model evaluation, J. Geophys. Res., 106, 8047-8075, 2001.

Shine, K. P., Bourqui, M. S., Forster, P. M. F., Hare, S. H. E., Langematz, U., Braesicke, P., Grewe, V., Ponater, M., Schnadt, C., Smith, C. A., Haigh, J. D., Austin, J., Butchart, N., Shindell, D. T., Randel, W. J., Nagashima, T., Portmann, R. W., Solomon, S., Seidel, D. J., Lanzante, J., Klein, S., Ramaswamy, V., and Schwarzkopf, M. D.: A comparison of model-simulated trends in stratospheric temperatures, Quart. J. R. Met. Soc., 129, 15651588, 2003.

Steil, B., Dameris, M., Brühl, C., Crutzen, P. J., Grewe, V., Ponater, M., and Sausen, R.: Development of a chemistry module for GCMs: first results of a multiannual integration, Ann. Geophys., 16, 205-228, 1998,

\section{SRef-ID: 1432-0576/ag/1998-16-205.}

Steil, B., Brühl, C., Manzini, E., Crutzen, P. J., Lelieveld, J., Rasch, P. J., Roeckner, E., and Krüger, K.: A new interactive chemistry climate model: 1 . Present day climatology and interannual variability of the middle atmosphere using the model and 9 years of HALOE/UARS data, J. Geophys. Res., 108, 4290, doi:10.1029/2002JD002971, 2003.

Steinbrecht, W., Claude, H., Köhler, U., and Hoinka, K. P.: Correlations between tropopause height and total ozone: implications for long-term changes, J. Geophys. Res., 103, 19 183-19192, 1998.

Steinbrecht, W., Claude, H., Köhler, U., and Winkler, P.: Interannual changes of total ozone and northern hemisphere circulation patterns, Geophys. Res. Lett., 28, 1191-1194, 2001.
Stenke, A. and Grewe, V.: Simulation of stratospheric water vapour trends: Impact on stratospheric ozone chemistry, Atmos. Chem. Phys., 5, 1257-1272, 2005,

SRef-ID: 1680-7324/acp/2005-5-1257.

Stott, P. A., Tett, S. F. B., Jones, G. S., Allen, M. R., Mitchell, J. F. B., and Jenkins, G. J.: External control of twentieth century temperature variations by natural and anthropogenic forcings, Science, 15, 2133-2137, 2002.

Wang, C. and Prinn, R. G.: Impact of emissions, chemistry, and climate on atmospheric carbon monoxide: 100-year predictions from a global chemistry-climate model, Chemosphere Global Change Science, 1, 77-81, 1999.

WMO (World Meteorological Organisation): Atmospheric Ozone 1985, Global Ozone Research and Monitoring Project, Report No. 16, 1986.

WMO (World Meteorological Organisation): Scientific Assessment of Ozone depletion: 1999, Global Ozone Research and Monitoring Project, Report No. 44, ISBN 92-807-1722-7, 1999.

WMO (World Meteorological Organisation): Scientific Assessment of Ozone depletion: 2002, Global Ozone Research and Monitoring Project, Report No. 47, ISBN 92-807-2261-1, 2003.

Yienger, J. J. and Levy II, H.: Empirical model of global soilbiogenic $\mathrm{NO}_{\mathrm{x}}$ emissions, J. Geophys. Res., 100, 11 447-11464, 1995.

Zhou, S., Gelman, M. E., Miller, A. J., and McCormack, J. P.: An inter-hemispheric comparison of the persistent stratospheric polar vortex, Geophys. Res. Lett., 27, 1123-1126, 2000.

Zhou, X. L., Geller, M. A., and Zhang, M. H.: Tropical cold point tropopause characteristics derived from ECMWF reanalysis and soundings, J. Clim., 14, 1823-1838, 2001. 